\title{
La administración de los derechos de autor en las revistas portuguesas, españolas y mexicanas de historia a través de sus modelos e instrumentos
}

\author{
Jenny Teresita Guerra González*
}

\section{Artículo recibido: \\ 30 de diciembre de 2018 \\ Artículo aceptado: \\ 20 de febrero de 2019}

Artículo de investigación

\section{Resumen}

Se describen y analizan los modelos e instrumentos mediante los cuales se administran los derechos de autor en las revistas portuguesas, españolas y mexicanas de historia. A través de una metodología cuantitativa, consistente en la revisión de los portales web y los contenidos del último número de una población de 46 publicaciones de esta disciplina, se encontró que: 1) España es el país que concentra la mayor cantidad de estas revistas; 2) $21.73 \%$ de las revistas analizadas tienen como modelo de administración de derechos los derechos de autor -también conocido como todos los derechos reservados-; $36.95 \%$ emplean el licenciamiento Creative Commons o alguna variante del copyleft; $34.78 \%$

* Instituto de Investigaciones Bibliotecológicas y de la Información, UNAM, México jenn_guerra@hotmail.com jennyguerra18@gmail.com INVESTIGACIÓN BIBLIOTECOLÓGICA, vol.33, núm. 79, abril/junio, 2019, México, ISSN:
2448-8321 pp. 205-240 
usan los derechos de autor y el licenciamiento de manera conjunta, y $6.52 \%$ no especifica en ningún apartado de su interfaz en línea o contenido el modelo con que gestiona los derechos de autor. De los siete instrumentos de administración de derechos de autor recomendados para la correcta gestión de los mismos, los tres más utilizados fueron el apartado específico de derechos de autor, el cintillo legal en la página de inicio y la declaración del tipo de acuerdo legal con el que operan en las instrucciones para autores.

Palabras clave: Revistas de Historia; Derechos de Autor; Copyleft; Instrumentos de Administración de Derechos de Autor

The administration of copyright in Portuguese, Spanish and Mexican journals of History through their models and instruments

Jenny Teresita Guerra González

\section{Abstract}

The models and instruments through which copyright is administered in the Portuguese, Spanish and Mexican journals of history are described and analyzed. Through a quantitative methodology, consisting of the review of the web portals and the contents of the last issue of a population of 46 publications of this discipline, we find that: 1 . Spain is the country that concentrates the largest number of these journals; 2. $21.73 \%$ of the analyzed journal are modeled on the administration of copyright; $36.95 \%$ use the Creative Commons license or some copyleft variant; $34.78 \%$ use the copyright and the licensing jointly and $6.52 \%$ is not specified in any section of its online interface or the model with the management of copyright. Finally, of the seven instruments of copyright administration the best of them in the same way of the same more than the rights of employees of the law of copyright, the legal headline on the home page and the declaration of the type of legal agreement with the work in the instructions for authors.

Keywords: History Journals; Copyright; Copyleft; Copyright Management Instruments 


\section{INTRODUCCIÓN}

T os derechos de autor son una de las materias primas de la academia, as-

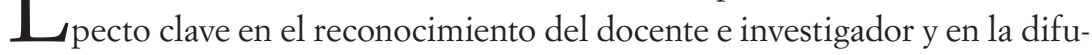
sión y comercialización de sus artículos, libros u otros productos de investigación. Específicamente los derechos de autor se definen como "los derechos de los creadores sobre sus obras, las cuales pueden comprender libros, música, pinturas, esculturas y películas e incluso anuncios, mapas y diseños técnicos" (Organización Mundial de la Propiedad Intelectual, 2016). Los derechos de autor "protegen sólo la forma, el modo de expresión y dejan dentro del dominio público la idea, la cual integra el fondo común de la humanidad" (Antequera Parilli, 2010: 127).

Respecto a los derechos de autor en el contexto de las revistas académicas y científicas es menester puntualizar que aquellos inician con el creador de la obra y no con el editor (Morrison, 2009: 81). Los editores adquieren el copyright cuando el autor o los autores de las obras les ceden o transfieren los derechos patrimoniales de su obra; empero, no es necesario transferir los derechos de autor para publicar y cada vez es más común que los autores los conserven ya sea a través de un acuerdo con el editor, una adición o vía una licencia abierta como las Creative Commons.

El derecho de autor en tanto conjunto de normas jurídicas y principios legales busca regular los usos ilegales de los materiales que amparan cada una de las legislaciones y simultáneamente restringir la utilización de las obras por parte de terceros mediante monopolios legales de derechos exclusivos. Las leyes de cada país en materia de derechos de autor establecen los plazos de protección; las limitaciones y excepciones así como el tipo de material sujeto a este derecho, y la exigencia de fijación en un soporte material. En el derecho de autor continental que rige en Iberoamérica se distinguen dos clases de facultades inherentes a la creación académica, pero también literaria y artística:

1. Derechos morales: facultades extrapatrimoniales que engloban principalmente el derecho a la paternidad de la obra, el derecho a la integridad (impedir cualquier deformación, modificación, alteración o atentado contra la obra) y el derecho de divulgación, es decir, a decidir la publicación y la forma en que ésta se difundirá;

2. Derechos patrimoniales: son derechos de explotación, de naturaleza patrimonial y transable. Las diferentes leyes nacionales utilizan distintos términos para describir los derechos englobados en esta 
categoría, pero en general incluyen: a) los derechos de reproducción, que implican la fabricación de copias o ejemplares tangibles, incluido el derecho de distribución de dichas copias o ejemplares al público; b) los derechos de transformación o de creación de obras derivadas basadas en la obra original, y c) el derecho de comunicación pública mediante la actuación, exhibición o puesta a disposición del público de la obra (Boretto, 2010: 79; Sádaba, 2008: 40, 188, 190).

En el ámbito de las revistas académicas y científicas es indispensable que, como parte de su política editorial, quede explícita la administración de los derechos de autor o política de derechos de autor, definida como la suma y administración de tres principios universales: 1) el derecho de autor protege la creación de obras; 2) la obra debe ser original, y 3 ) la indiferencia del destino de las obras (Colombet, 1997). Específicamente la administración de los derechos de autor es el proceso de selección de un modelo de derechos de autor, entendido éste como normativa (derechos de autor o copyleft/licenciamiento: inserción normativa del copyright ${ }^{1}$ ), y su implementación por medio de instrumentos y documentos formales que competen al editor, al autor y a la publicación misma.

En atención a los precedentes mencionados, este trabajo tiene como objetivo describir y analizar los modelos e instrumentos mediante los cuales se administran los derechos de autor en las revistas portuguesas, españolas y mexicanas de historia. Se parte de esta hipótesis: la ausencia de un estándar de administración de derechos de autor lleva a que las revistas portuguesas, españolas y mexicanas de historia, así como las publicaciones académicas en general, gestionen incorrectamente la propiedad intelectual de los contenidos de terceros, incurriendo en faltas legales y éticas.

1 El concepto de copyleft es una implementación del copyright. Surgió con el propósito de proteger la libre circulación del código informático y del conocimiento que encierra. Utiliza la legislación de copyright para proteger la libertad de copia, modificación y redistribución, en vez de restringirlas. Trabaja como sistema que permite la libre distribución de copias y versiones modificadas de un trabajo u obra (Economía simple, 2016). 
DERECHOS DE AUTOR Y COPYLEFT O LICENCIAMIENTO COMO MODELOS NORMATIVOS DE ADMINISTRACIÓN DE DERECHOS DE AUTOR A PARTIR DE LA CESIÓN

El tema de la cesión entre autor y editorial, entendido como el acuerdo entre dos partes en las que se establecen los términos de reproducción, distribución y uso de una creación intelectual, es uno de los puntos cruciales a tratar en el campo de las revistas académicas y científicas. La "cesión" implica la transmisión de las facultades de carácter patrimonial o derechos de explotación sobre la obra, misma que tiene variados matices:

a) La revista retiene los derechos de autor patrimoniales de las contribuciones. Adquiere el uso exclusivo del documento para editarse, difundirse, preservarse, etc. en cualquier soporte y por el tiempo que estipule la legislación local que regule la actuación de la publicación. Se manifiesta por una declaración explícita en el reglamento interno; cartas o documentos de autorización de publicación; avisos de derechos de autor y/o directrices para autores de las publicaciones;

b) Los derechos de autor patrimoniales quedan en manos del autor. La política editorial de la revista hace mención de la no retención de los derechos de autor, conminando a los académicos a concretar otros acuerdos contractuales con editores o publicaciones distintas; depositar versiones preliminares en repositorios, servidores de preprints o páginas personales, $\mathrm{y}$

c) El autor y la revista comparten los derechos patrimoniales. Mediante acuerdo contractual o de índole similar, los autores dan a la revista un permiso o autorización de primera publicación, sobre la que aquella tiene los derechos (versión del editor) pero no sobre documentos preliminares o posteriores (Melero y Abad García, 2008).

Tradicionalmente, los editores comerciales o que distribuyen sus publicaciones bajo el modelo de negocio de suscripciones utilizan un acuerdo de cesión o transferencia de derechos; con este documento los autores ceden todos o parte de sus derechos patrimoniales. En los tres países que nos ocupan, las legislaciones en la materia establecen lo siguiente:

- Portugal. Código do Direito de Autor e dos Direitos Conexos (conforme alterado de acordo com Lei n. ${ }^{\circ}$ 16/2008, de 01/04) (2008):

Artículo 40 (Disponibilidad de los poderes patrimoniales). El titular originario, así como sus sucesores o transmisores, podrán: a) autorizar la utilización de la obra por tercer; b) Transmitir o cargar, total o 
parcialmente, contenido patrimonial del derecho de autor sobre esta obra; [...]

Artículo 44 (Transmisión total). La transmisión total y definitiva del contenido patrimonial del derecho de autor sólo puede ser efectuada por escritura pública, con identificación de la obra e indicación del precio en su caso, bajo pena de nulidad.

- España. Ley de Propiedad Intelectual (1996):

Artículo 17. Derecho exclusivo de explotación y sus modalidades. Corresponde al autor el ejercicio exclusivo de los derechos de explotación de su obra en cualquier forma y, en especial, los derechos de reproducción, distribución, comunicación pública y transformación, que no podrán ser realizadas sin su autorización, salvo en los casos previstos en la presente Ley; [...]

Artículo 45. Formalización escrita. Toda cesión deberá formalizarse por escrito. $\mathrm{Si}$, previo requerimiento fehaciente, el cesionario incumpliere esta exigencia, el autor podrá optar por la resolución del contrato.

- México: Ley Federal del Derecho de Autor (1996):

Artículo 24. En virtud del derecho patrimonial, corresponde al autor el derecho de explotar de manera exclusiva sus obras, o de autorizar a otros su explotación, en cualquier forma, dentro de los límites que establece la presente Ley y sin menoscabo de la titularidad de los derechos morales a que se refiere el artículo 21 de la misma; [...]

Artículo 30. El titular de los derechos patrimoniales puede, libremente, conforme a lo establecido por esta Ley, transferir sus derechos patrimoniales u otorgar licencias de uso exclusivas o no exclusivas.

Toda transmisión de derechos patrimoniales de autor será onerosa y temporal. En ausencia de acuerdo sobre el monto de la remuneración o del procedimiento para fijarla, así como sobre los términos para su pago, la determinarán los tribunales competentes.

Los actos, convenios y contratos por los cuales se transmitan derechos patrimoniales y las licencias de uso deberán celebrarse, invariablemente, por escrito, de lo contrario serán nulos de pleno derecho.

Los marcos legales de los tres países en que se ubican las publicaciones sobre las que se efectuó la investigación derivan del modelo de derechos de autor europeo, que identifica al autor como la persona que crea la obra; sin embargo, la titularidad puede o no corresponderle. Los titulares del derecho de autor son las personas físicas o jurídicas que tienen la propiedad de la obra y 
disponen de ella. La titularidad se adquiere por estas circunstancias: creación original (obra primigenia) o derivada (modificaciones, traducciones, adaptaciones, etcétera); por la muerte del autor, en cuyo caso los herederos serán causahabientes o titulares derivados del derecho de autor; por asignación de la ley y por el acto jurídico convencional (contrato). Las leyes nacionales establecen una nómina taxativa o enunciativa de los titulares del derecho de autor, y suelen considerar situaciones particulares (Boretto, 2017: 255-256).

El contrato de cesión de derechos de autor, eje de este modelo de administración de derechos, consigna los siguientes aspectos:

- El autor o titular del derecho (cedente);

- El tercero que recibe los derechos (cesionario);

- Los derechos objeto de cesión y su modalidad. Existen tantos derechos de reproducción, distribución, comunicación pública, transformación, etc. - como formas de explotación -digital, impresa, audiovisual-. Por ello, al momento de celebrar un contrato de esta naturaleza, es fundamental que el autor o el titular del derecho identifique claramente cuáles derechos desea ceder;

- El tiempo durante el cual se cederán o se otorgarán esos derechos. La cesión de los derechos se concede por un tiempo, al cabo del cual dichos derechos vuelven al autor o al titular. Muchos de los contratos establecen que la cesión es por el tiempo máximo establecido por la ley, situación que priva al autor o al titular del derecho de su obra de por vida, ya que dicho plazo equivale a la vida del autor y, como mínimo, 50 años más después de su muerte;

- El espacio donde se podrán explotar los derechos cedidos. Al momento de suscribir el contrato, el autor deberá determinar el espacio geográfico en el cual se podrán explotar los derechos concedidos;

- Si la cesión es exclusiva o no. Dependiendo del acuerdo al que hayan llegado las partes involucradas sus efectos son diferentes:

a) Cesión exclusiva: el cesionario es el único con la facultad para explotar la obra de conformidad con los derechos concedidos a través del contrato y durante el tiempo pactado. Esta exclusividad impide a todas las demás personas, incluso al cedente-autor, explotar la obra, aun siendo este último su creador;

b) Cesión no exclusiva: el cedente-autor puede realizar otros contratos de cesión, incluso sobre los mismos derechos objeto del contrato que firmó y explotarlos por su propia cuenta (Centro Regional para el Fomento del Libro en América Latina y el Caribe, 2011). 
Un segundo modelo de administración de derechos de autor, entendido como implementación del copyright o esquema anglosajón de derechos de autor, es el copyleft, que con base en la posibilidad de decisión del autor define una serie de derechos para el beneficiario de la obra. Es una respuesta a la cantidad de opciones y posibilidades existentes respecto a la manera en que es factible llevar a cabo la explotación de las obras intelectuales, científicas y artísticas en un momento en el que los derechohabientes han perdido el control sobre la copia debido a la realidad tecnológica y económica.

El copyleft faculta al autor para ejercer de manera personal los derechos no cedidos al editor en relación a su obra, pudiendo autorizar su utilización para fines educativos o de investigación, su difusión inmediata o diferida, su futura reutilización y su preservación a largo plazo. La importancia de retener ciertos derechos facilita que los autores tengan mayor control sobre el uso de su trabajo y al mismo tiempo se garantiza que el editor explote comercialmente la obra sin que haya de por medio una transferencia de derechos (Melero, 2010: 6). Una vez que se conocen las modalidades de explotación y las alternativas a la reserva de derechos que considere el autor se recurre a las licencias de uso. Las licencias son el conjunto de condiciones bajo las cuales el autor decide que su obra sea usada (explotada). Éstas tienen un carácter de permiso otorgado por el titular del derecho, en cualquier forma contractual, para utilizar la obra en alguno de los modos y por alguno de los medios que establecen las distintas legislaciones nacionales en términos de derecho de autor (Boretto, 2010: 47).

A diferencia de un acuerdo de cesión o transferencia de derechos, la licencia es un simple permiso de uso de naturaleza personal, con el alcance convenido por las partes, y sobre la cual el titular, licenciante o autor conservará la propiedad. Entre las licencias de uso más recurrentes encontramos las licencias a la carta. Éstas permiten decidir qué se puede hacer con la obra a través de filtros. Un ejemplo de ellas son las licencias Creative Commons (CC). Su función principal es autorizar los usos de la obra o creación y simultáneamente informar a los potenciales usuarios sobre lo que el titular de los derechos de autor permite o no permite hacer con su trabajo. Las licencias CC regulan los derechos de explotación de una obra (reproducción, distribución, comunicación pública y transformación) mediante seis modalidades: 1) Atribución, 2) Atribución-No Derivadas, 3) Atribución-No Comercial-No Derivadas, 4) Atribución-No Comercial, 5) Atribución-No Comercial-Licenciamiento Recíproco, y 6) Atribución-Licenciamiento Recíproco ("Módulo 7. Licenciamiento Creative Commons”, 2013). 


\section{INSTRUMENTOS PARA LA ADMINISTRACIÓN DE DERECHOS DE AUTOR EN}

\section{REVISTAS ACADÉMICAS}

Un instrumento se conceptualiza como cualquier objeto o recurso que se emplea como medio para arribar a un fin (De Conceptos, 2018). En ese sentido, los instrumentos para la administración de derechos de autor son una serie de pautas que se necesitan para administrar correctamente los dos tipos de modelos de derechos de autor (derechos de autor y copyleft o licenciamiento) por parte de editoriales, instituciones u organizaciones que publican revistas académicas. Los instrumentos tienen la función de informar a los autores sobre las condiciones en que se publicarán y distribuirán sus contribuciones en las distintas versiones -impresa y/o digital- de la revista además de los usos alternos que puedan o no hacer de las mismas en lo inmediato y futuro. También han de operar en dos sentidos: a) como indicaciones de los usos y reúsos que los lectores tienen permitido hacer de esos materiales, y b) como mecanismo de transparencia y ética editorial de la publicación.

Si bien actualmente se carece de un consenso sobre cuáles son los instrumentos de administración de derechos de autor indispensables en la política editorial de una revista, a continuación se enlistan y detallan los más citados en manuales editoriales, directrices de organismos internacionales sobre la materia, sistemas de indización y artículos científicos. De igual manera se menciona el lugar que han de ocupar en la interfaz de los gestores editoriales o sitios web de las revistas académicas y/o en su contenido individual (Tabla 1).

\begin{tabular}{|c|c|c|}
\hline $\begin{array}{l}\text { Nombre del instrumento/Des- } \\
\text { cripción }\end{array}$ & $\begin{array}{l}\text { Lugar de la interfaz web o } \\
\text { del contenido individual en } \\
\text { que debe localizarse }\end{array}$ & $\begin{array}{c}\text { Modelo de administración } \\
\text { de derechos de autor en el } \\
\text { que se utiliza }\end{array}$ \\
\hline $\begin{array}{l}\text { Aviso de derechos de autor/a o Nota } \\
\text { de copyright } \\
\text { Declaración que identifica al } \\
\text { propietario del derecho de autor, } \\
\text { los usos que permite de la obra y su } \\
\text { fecha de creación }\end{array}$ & $\begin{array}{l}\text { Apartado específico de } \\
\text { "Envíos" }\end{array}$ & $\begin{array}{l}\text { Derechos de autor y } \\
\text { copyleft }\end{array}$ \\
\hline $\begin{array}{l}\text { Instrucciones para autores } \\
\text { Serie de requisitos de forma, fondo } \\
\text { y legales que deben cumplir los } \\
\text { potenciales autores para enviar } \\
\text { sus manuscritos a la publicación } \\
\text { en cuestión }\end{array}$ & $\begin{array}{c}\text { Apartado específico de } \\
\text { "Envíos" }\end{array}$ & $\begin{array}{c}\text { Derechos de autor y } \\
\text { copyleft }\end{array}$ \\
\hline
\end{tabular}




\begin{tabular}{|c|c|c|}
\hline $\begin{array}{c}\text { Cintillo legal } \\
\text { Leyenda que detalla el régimen } \\
\text { de propiedad - derechos de autor } \\
\text { o copyleft-de la publicación y su } \\
\text { contenido (incluye año y nombre de } \\
\text { la organización o empresa editora) }\end{array}$ & $\begin{array}{c}\text { Parte inferior de la primera } \\
\text { página de la interfaz web de } \\
\text { la revista }\end{array}$ & $\begin{array}{c}\text { Derechos de autor y } \\
\text { copyleft }\end{array}$ \\
\hline $\begin{array}{c}\text { Política de acceso abierto } \\
\text { Declaración de adherencia a las po- } \\
\text { líticas de acceso abierto que dan el } \\
\text { derecho a los lectores a descargar, } \\
\text { imprimir, compartir o vincular el } \\
\text { texto completo de cualquiera de los } \\
\text { artículos publicados en cualquiera } \\
\text { de los números publicados }\end{array}$ & $\begin{array}{c}\text { Apartado específico de } \\
\text { "Políticas" }\end{array}$ & Copyleft \\
\hline $\begin{array}{c}\text { Información orientada a los lectores } \\
\text { sobre el esquema de distribución, } \\
\text { uso y reúso del material que están } \\
\text { consultado }\end{array}$ & $\begin{array}{c}\text { En cada uno de los formatos } \\
\text { de archivo en que se encuen- } \\
\text { tren los artículos u otro tipo de } \\
\text { contribuciones que publique } \\
\text { la revista }\end{array}$ & Derechos de autor y \\
copyleft
\end{tabular}

Tabla 1. Instrumentos de administración de derechos de autor con los que deben cumplir las revistas académicas Fuente: elaboración propia a partir de Aparicio, Banzato y Liberatore (2016), Latindex (2017) y Rojas y Rivera (2011)

Los seis instrumentos mencionados no son excluyentes de otros que utilicen en el presente inmediato o que puedan utilizar las revistas académicas en el corto y mediano plazo con independencia de su modelo de administración de derechos de autor. Éstos son producto de los constantes cambios tecnológicos y legales.

\section{Metodología}

La metodología empleada en este trabajo fue cuantitativa, que utiliza la recolección y el análisis de datos para contestar preguntas de investigación y probar hipótesis establecidas previamente; se basa en la medición numérica, el conteo y el uso de estadística para establecer patrones de comportamiento en una población (Tamayo y Tamayo, 2004: 60). En este caso el objetivo, como se recordará, consiste en describir y analizar los modelos e instrumentos mediante los cuales se administran los derechos de autor en las revistas portuguesas, españolas y mexicanas de historia. Así, el primer paso consistió 
en delimitar la población de revistas portuguesas, españolas y mexicanas de historia del estudio -que incluye los campos de la historia como disciplina/ ciencia, historia económica, historia del arte, historia nacional, historia de la ciencia, etc.-. Dicha población se obtuvo a partir de las publicaciones indizadas en SciELO Portugal (http://www.scielo.mec.pt/scielo.php?script=sci_subject\&lng=pt\&nrm=iso\#subj4), la Fundación Española para la Ciencia y la Tecnología (https://evaluacionarce.fecyt.es/documentos/ListadoSelloFECYT.pdf) y el Sistema de Clasificación de Revistas Mexicanas de Ciencia y Tecnología (http://www.revistascytconacyt.mx/index.php/revistas/area/4).

En un segundo momento, previo conocimiento de los modelos de administración de derechos de autor existentes y sus instrumentos, se procedió a identificarlos en la interfaz web y en los contenidos unitarios del último número publicado de cada revista. La obtención de tales datos se realizó en la semana del 4 al 13 de junio de 2018 (Anexo).

La información recopilada, presentada y analizada en el subsecuente apartado, permitirá corroborar o descartar la hipótesis del trabajo, es decir, la ausencia de un estándar de administración de derechos de autor lleva a que las revistas portuguesas, españolas y mexicanas de historia así como las publicaciones académicas en general gestionen incorrectamente la propiedad intelectual de los contenidos de terceros, incurriendo en faltas legales y éticas.

\section{Resultados Y DisCUSIÓN}

La población seleccionada para efectuar la investigación está compuesta por un total de 46 revistas de historia publicadas en tres países de la región iberoamericana; de aquellas, cuatro $(8.70 \%$ ) son editadas en Portugal, 34 (73.91 \%) en España y ocho (17.39 \%) en México (Figura 1). Considerando la relevancia del modelo de negocio de las publicaciones en la elección-coincidencia de su modelo de administración de derechos, se encontró que el acceso abierto es el modelo más recurrente: $75 \%$ de las revistas portuguesas optaron por él; $88 \%$ de las españolas y $100 \%$ de las mexicanas publican bajo este esquema (Figura 2), lo cual puede entenderse si observamos que las instituciones que editan esas revistas son organizaciones con financiamiento público para esta y otras actividades, que han de divulgar sus productos de investigación a la sociedad sin ánimo de lucro. Empero, en España, país iberoamericano que concentra el esfuerzo en la edición de revistas de historia, se localizaron dos publicaciones que se distribuyen bajo el modelo de acceso abierto con embargo de 24 meses y cuatro revistas están disponibles sólo para suscriptores o en el esquema de acceso cerrado. De manera paralela en 
Portugal, nación con el menor número de publicaciones en este campo, fue ubicada una sola revista en el esquema de acceso abierto con embargo de seis meses.

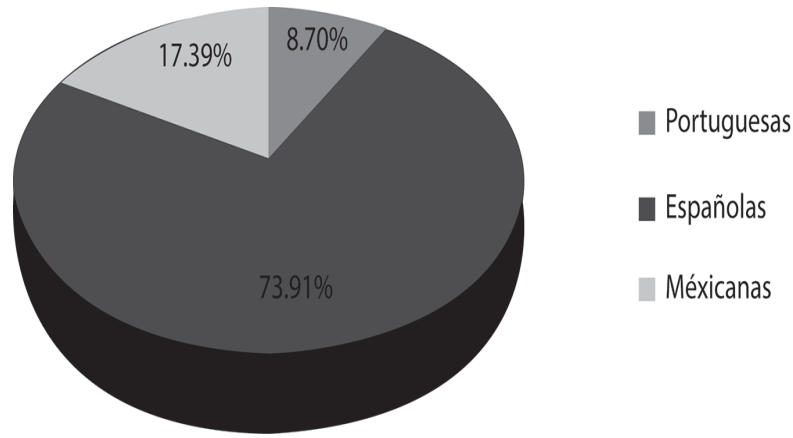

Figura 1. Porcentaje de revistas de historia publicadas en Portugal, España y México Fuente: elaboración propia con datos del estudio

Acceso abierto $\quad$ Acceso restringido

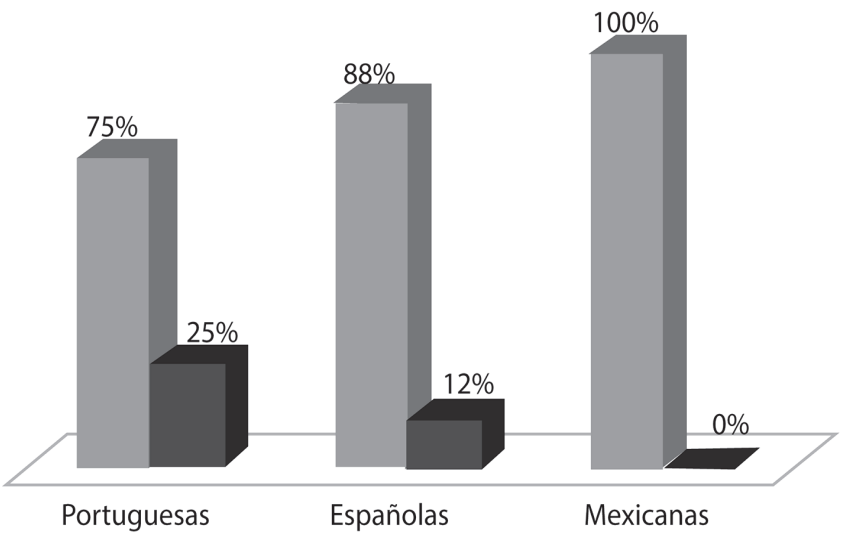

Figura 2. Porcentaje de revistas portuguesas, españolas y mexicanas de historia cuyo modelo de negocio es el Acceso Abierto Fuente: elaboración propia con datos del estudio

Respecto a la selección de un modelo de administración de derechos de autor (derechos de autor, licenciamiento o ambos); la revisión de los gestores editoriales y/o sitios web de las revistas objeto de estudio arrojó que 21.73 \% 
(10) de las publicaciones utilizan el de derechos de autor; $36.95 \%$ (17) emplean el licenciamiento CC o alguna variante del copyleft; $34.78 \%$ (16) usan derechos de autor y licenciamiento de manera conjunta e incluso contradictoria y $6.52 \%$ (3) no especifica en ningún apartado de su interfaz en línea o contenido el modelo con que gestiona los derechos de autor (Figura 3).

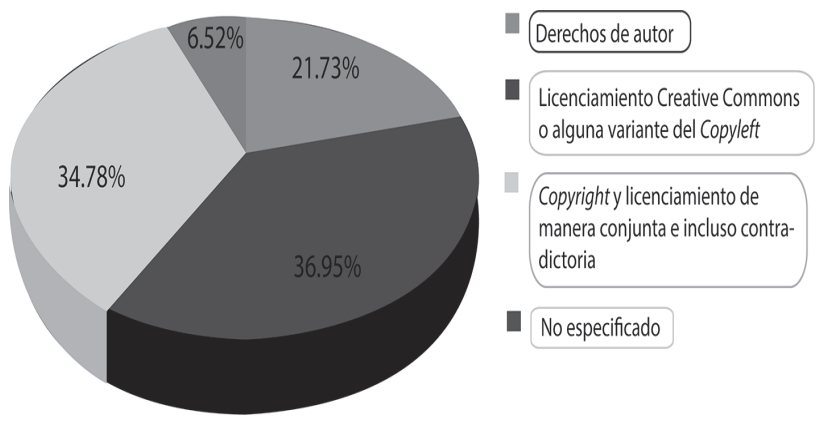

Figura 3. Distribución porcentual de revistas portuguesas, españolas y mexicanas de historia por modelo de administración de derechos de autor Fuente: elaboración propia con datos del estudio

De los seis instrumentos de administración de derechos de autor recomendados para la correcta gestión de los mismos en plataformas y contenidos editoriales de revistas científicas en línea, más uno que se ubicó tras la recolección de los datos, se encontró que de las 46 publicaciones portuguesas, españolas y mexicanas de historia $41.30 \%$ (19) utilizan cintillo legal en su página de inicio; $34.78 \%$ (16) declaran el tipo de acuerdo legal con el que operan en las instrucciones para autores; $58.69 \%$ (27) incluyen un apartado específico de derechos de autor; $17.39 \%$ (8) mencionan las condiciones de uso y reúso de sus materiales en la denominada política de acceso abierto; $34.78 \%$ (16) especifican a los lectores el esquema de distribución, uso y reúso del material en los artículos y otras contribuciones de forma individual; $8.69 \%$ (4) regulan los aspectos legales de los textos que publican mediante reglamentos, estatutos o políticas internas y $23.91 \%$ (11) incorporan un documento formal para la autorización exclusiva, no exclusiva, vía condiciones señaladas en una licencia a la carta -del tipo Creative Commons- de la publicación, distribución o transferencia de los derechos de autor patrimoniales de autores a editores, revistas o instituciones (Figura 4). 


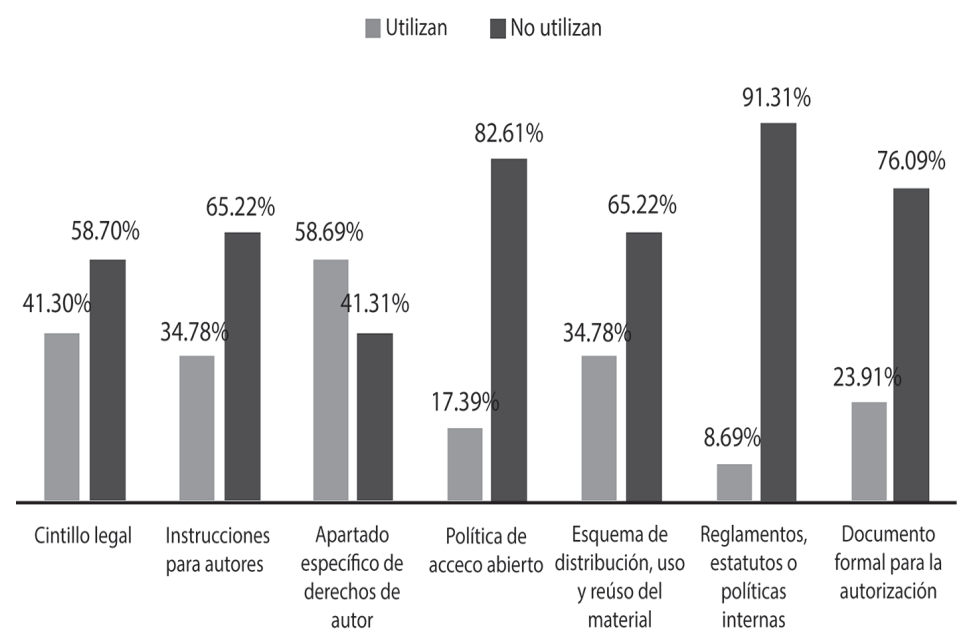

Figura 4. Porcentaje de revistas que utilizan los diferentes instrumentos de administración de derechos de autor Fuente: elaboración propia con datos del estudio.

Como se mencionó, la correcta administración de derechos de autor conlleva necesariamente una aplicación integral de un nutrido número de instrumentos de aquel tipo por parte de las revistas de historia o de cualquier otra disciplina. Aquellas condiciones motivan el uso de la noción de completud (cualidad de completo, Diccionario de la Lengua Española, 2018) para calificar el cumplimiento total o parcial de estos requisitos. Así, hablamos de una mayor completud cuando las publicaciones del estudio utilizan cuatro o más instrumentos de administración de derechos de autor, como fue el caso de ocho revistas (17\%) y de una menor completud, si las revistas emplean dos o menos instrumentos, situación que aconteció con 23 publicaciones $(50 \%)$ de la población estudiada (Figura 5). Si bien el número de revistas enfocadas en la disciplina de la historia es disímil entre los tres países sobre los que se realizó la investigación, es viable identificar sobre su población local el porcentaje de publicaciones que presentan un mayor uso de instrumentos de administración de derechos. Así, tenemos que para el caso portugués, dos de las cuatro revistas existentes (50\%) usan tres instrumentos; en España las publicaciones que sobresalieron por utilizar más instrumentos -un promedio de cuatro- representan $24 \%$ (ocho de 34 revistas nacionales) mientras que en México dos revistas (25\%) de un total de ocho presentaron el más amplio uso de instrumentos de administración de derechos, esto es, tres (Figura 6). 


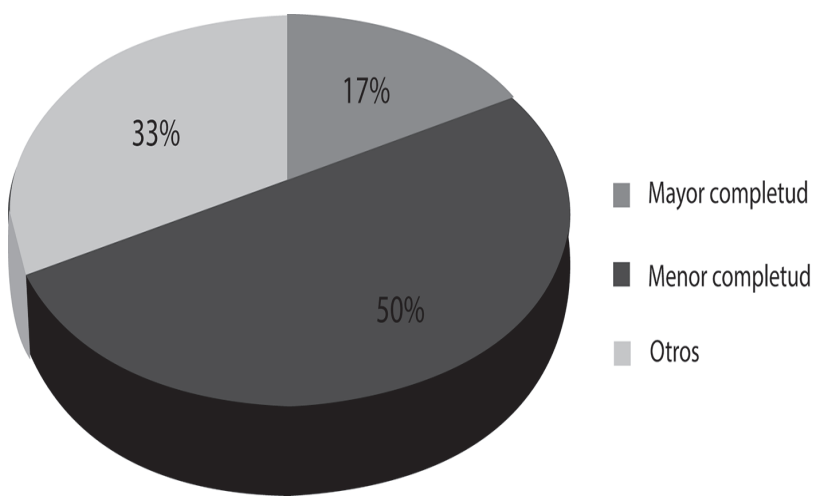

Figura 5. Porcentaje de revistas que emplean el mayor y el menor número de instrumentos de administración de derechos de autor respectivamente Fuente: elaboración propia con datos del estudio

Uso mayor de instrumentos Uso menor de instrumentos

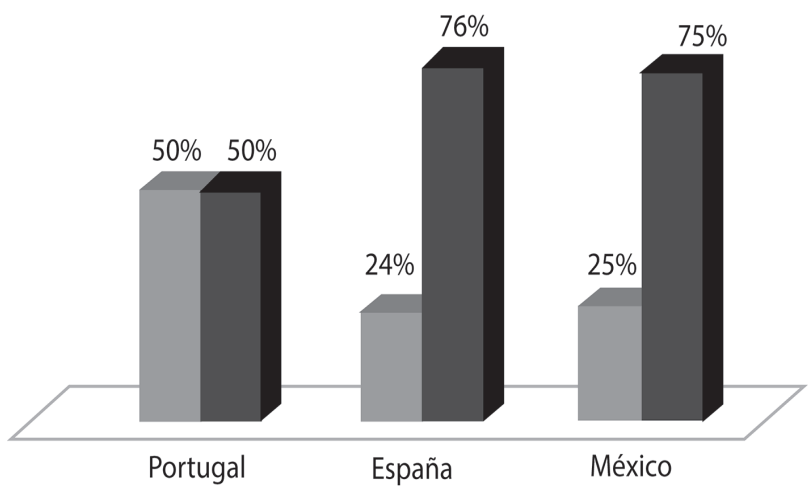

Figura 6. Porcentaje de revistas que por país presentan el mayor grado de completud en el uso de instrumentos de administración de derechos de autor Fuente: elaboración propia con datos del estudio

Al establecer una correlación entre modelo de negocio y modelo de administración de derechos de autor en las revistas portuguesas, españolas y mexicanas de historia se halló que 19.56 \% (nueve) de las publicaciones seleccionadas- en acceso abierto con o sin embargo utilizan únicamente el 
licenciamiento como parte de su política de administración de derechos de autor (Figura 7). Mediante la acción precedente, las revistas se alinean con las Directrices para Politicas de Desarrollo y Promoción del Acceso Abierto de la Unesco. Por otro lado, de cuatro de las revistas que utilizan como modelo de negocio la suscripción, $100 \%$ administra los derechos de autor con derechos de autor. Una publicación, la Revista de Historia Industrial. Economía y Empresa (Universidad de Barcelona) establece en el "apartado específico de derechos de autor" que si bien el/la autor/a cede en exclusiva todos los derechos de propiedad intelectual al/la editor/a para todo el mundo y toda la duración de los derechos de propiedad intelectual vigentes aplicables, aquel difundirá los textos con la licencia Creative Commons Reconocimiento 3.0 España.

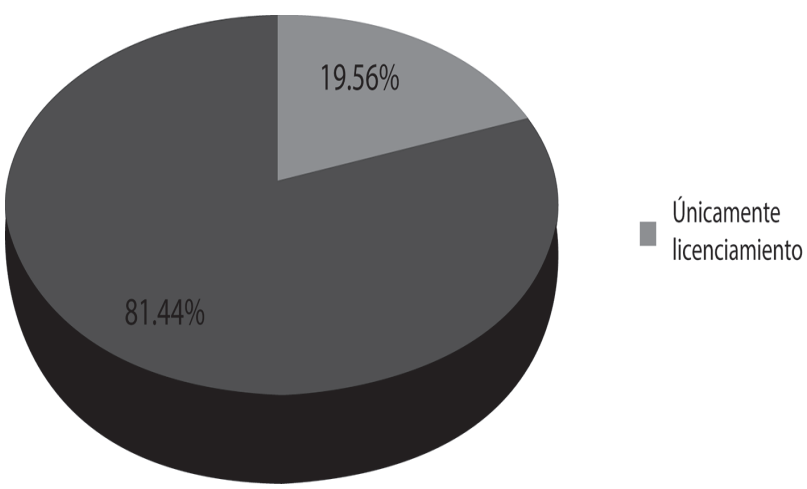

Figura 7. Porcentaje de revistas en acceso abierto con o sin embargo que utiliza únicamente el licenciamiento como parte de su política de administración de derechos de autor Fuente: elaboración propia con datos del estudio

\section{CONCLUSIONES Y RECOMENDACIONES}

Esta investigación evidenció el desconocimiento sobre la adecuada gestión de los modelos de administración de derechos de autor y sus instrumentos de parte de los editores de las revistas portuguesas, españolas y mexicanas de historia. Tales modelos e instrumentos son inconsistentes, incompletos, poco transparentes y las más de las veces, contradictorios. La carencia de un están$\mathrm{dar}^{2}$ formal y de uso generalizado por organismos de editores y sistemas de indización es, en ese sentido, una de sus principales causas. Este fenómeno, 
suponemos, no sólo se restringe a las publicaciones de esta disciplina sino al conjunto de las revistas académicas en los tres países del estudio y a nivel internacional.

Es necesario que los editores académicos y científicos tomen conciencia de las faltas legales y éticas en las que incurren al no informar adecuada y oportunamente a sus posibles autores y lectores sobre cómo gestionan los derechos de autor de los materiales que publican y distribuyen. A ese respecto se propone una primera versión de un estándar de administración de derechos de autor que contemple estos siete criterios/instrumentos -el séptimo sólo para las revistas que manejen el acceso abierto como modelo de negocio y el copyleft como esquema de derechos de autor- y que las publicaciones deben cumplir obligatoriamente si desean ser evaluadas favorablemente en términos de la posesión de una política de derechos de autor:

1. Cintillo legal en la primera página-impresa/digital-de la revista;

2. Reglamento interno de la revista que incluya como obligaciones de los editores informar de manera integral sobre el esquema de derechos de autor a lectores y autores;

3. Instrucciones para autores. Informará a los autores el esquema de derechos de autor que maneja la publicación y lo que implica para ellos como creadores intelectuales de los manuscritos;

4. Documento de autorización de publicación que detalle las condiciones con las que los autores de los artículos u otras contribuciones ceden total, parcialmente u otorgan ciertos permisos de uso y/o reúso a la revista y sus lectores;

5. Aviso de derechos de autor, que reafirma el modelo de administración de derechos de autor que ejecuta la publicación de manera puntual y en términos que autores y lectores entienden fácilmente;

6. Todas las versiones de las contribuciones (formatos de archivo) han de incluir en su primera página el régimen de derechos de autor con los que se distribuyen así como los usos permitidos o no;

7. Política de acceso abierto que especifique a autores y potenciales lectores los usos y reúsos de los materiales publicados.

\section{REFERENCIAS}

Antequera Parilli, Ricardo. 2010. "El derecho de autor en el ámbito universitario. Comentarios de jurisprudencia”. Propiedad Intelectual 9 (13): 124-149.

Aparicio, Alicia, Guillermo Banzato y Gustavo Liberatore. 2016. Manual de Gestión Editorial de Revistas Cientificas de Ciencias Sociales y Humanas. Buenas Prácticas y Criterios de Calidad. Buenos Aires: CLACSO. 
Boretto, Mónica. 2010. Contratos de edición: guía de licencias y cesión de derechos, derechos de autor, E-books y el entorno digital. Buenos Aires: Biblioteca de Francia.

Boretto, Mónica. 2017. "Los derechos de autor en la sociedad de la información", en La edición de libros en tiempos de cambio. Ciudad de México: Paidós.

Centro Regional para el Fomento del Libro en América Latina y el Caribe. 2011. La transmisión de los derechos y las licencias. Bogotá: Centro Regional para el Fomento del Libro en América Latina y el Caribe.

Código do Direito de Autor e dos Direitos Conexos (conforme alterado de acordo com Lein. ${ }^{\circ}$ 16/2008, de 01/04). 2008. Lisboa: Diario do Governo.

Colombet, Claude. 1997. Grandes principios del derecho de autor y los derechos conexos en el mundo. Estudio de derecho comparado. Madrid: Unesco/CINDOC.

De Conceptos. 2018. Concepto de instrumento. Madrid: De Conceptos.

Diccionario de la Lengua Española. 2018. Madrid: Real Academia Española.

Economía simple. 2016. Definición de copyleft. Valencia: Economía simple.

Latindex. 2017. Catálogo Latindex. Nueva lista de características de calidad editorial. Ciudad de México: Latindex.

Ley de Propiedad Intelectual. 1996. Madrid: Ministerio de Cultura.

Ley Federal del Derecho de Autor. 1996. Ciudad de México: Diario Oficial de la Federación.

Melero, Remedios y María Francisca Abad García. 2008. "Revistas open access: características, modelos económicos y tendencias”. BiD: textos universitaris de biblioteconomia i documentació 20 (9).

Melero, Remedios. 2010. Guía práctica sobre los derechos patrimoniales o de explotación (copyright) y su relación con el auto-archivo en repositorios de acceso abierto. Barcelona: Grupo de Trabajo de Acceso a la Ciencia.

"Módulo 7 - Licenciamiento Creative Commons y el movimiento del Acceso Abierto”. 2013. En ABC del derecho de autor para bibliotecarios de América Latina. Bogotá: Fundación Karisma/Internet Activa.

Morrison, Heather. 2009. Scholarly communication for librarians. Cambridge: Chandos Publishing.

Organización Mundial de la Propiedad Intelectual. 2016. Sobre la Propiedad Intelectual. Ginebra: Organización Mundial de la Propiedad Intelectual.

Rojas, María Alejandra y Sandra Rivera. 2011. Guía de Buenas Prácticas para Revistas Académicas de Acceso Abierto. Santiago de Chile: ONG Derechos Digitales.

Sádaba, Igor. 2008. Propiedad intelectual. ¿Bienes públicos o mercancías privadas? Madrid: Los Libros de la Catarata.

Tamayo y Tamayo, Mario. 2004. El proceso de la investigación cientifica. México: Limusa.

Para citar este texto:

Guerra González, Jenny Teresita. 2019. “La administración de los derechos de autor en las revistas portuguesas, españolas y mexicanas de historia a través de sus modelos e instrumentos". Investigación Bibliotecológica: archivonomía, bibliotecología e información 33 (79): 205-240. http://dx.doi.org/10.22201/iibi.24488321xe.2019.79.58066 

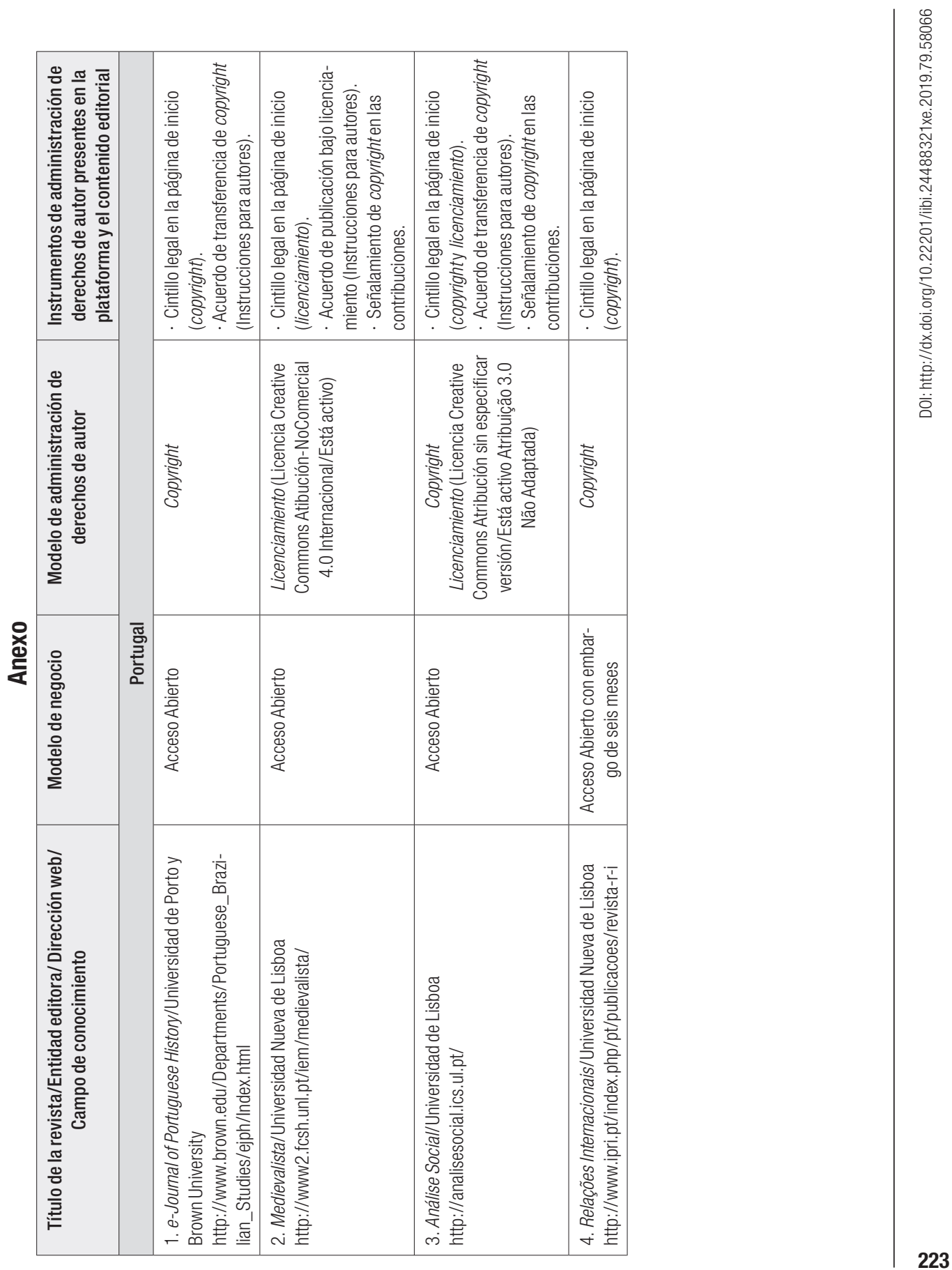


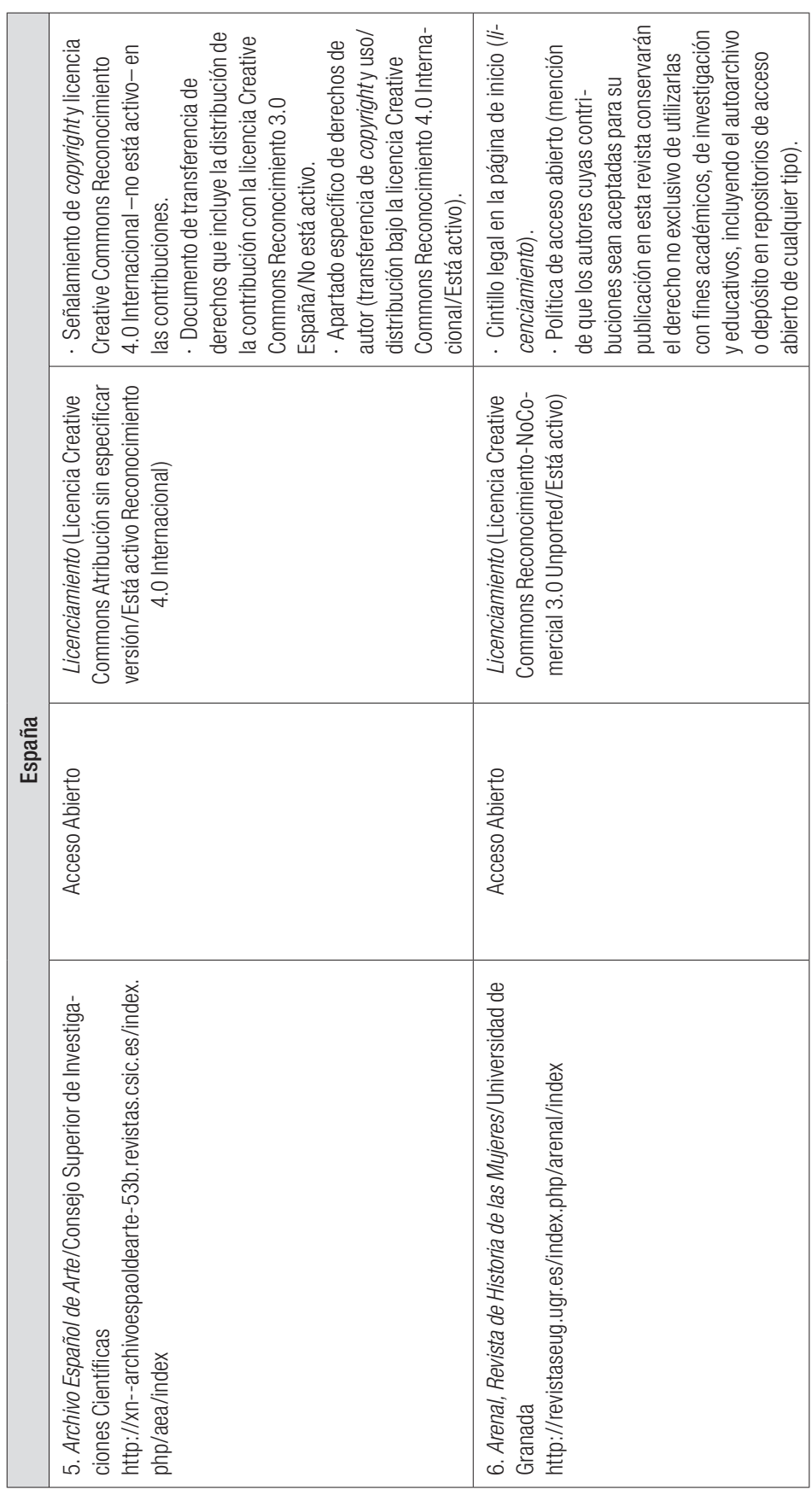




\begin{tabular}{|c|c|}
\hline 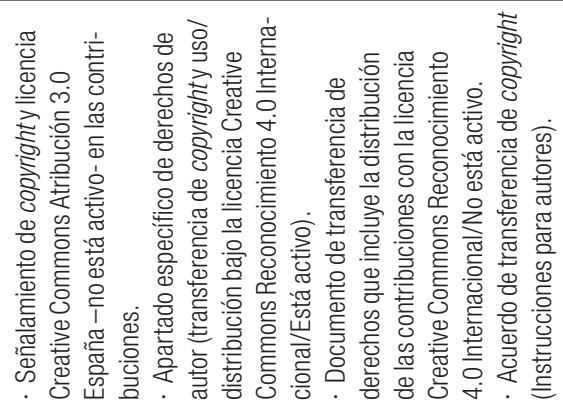 & 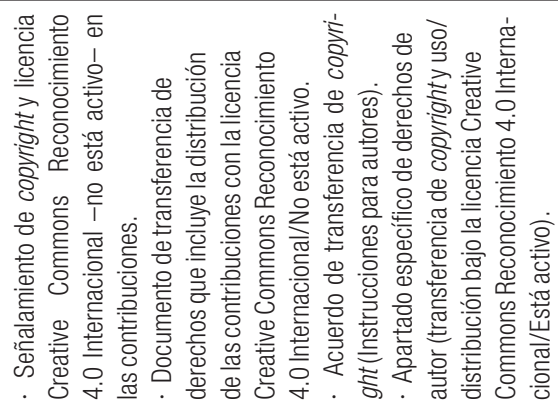 \\
\hline 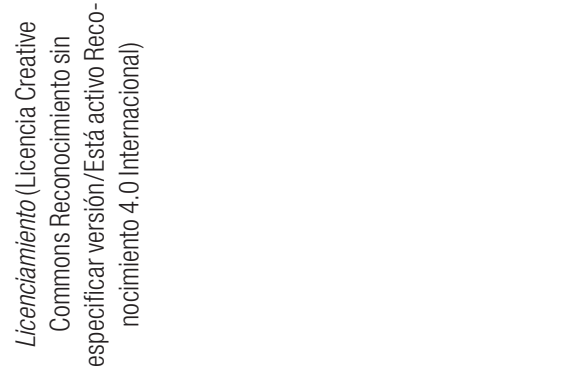 & 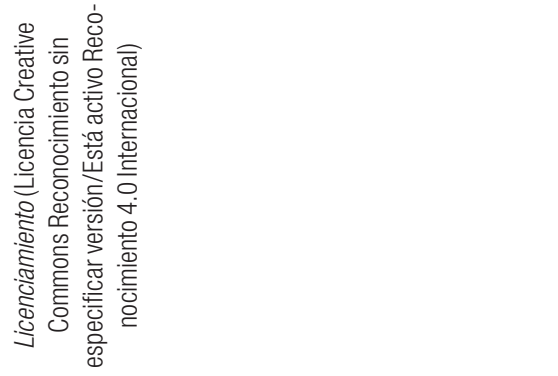 \\
\hline 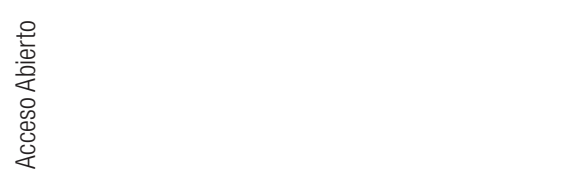 & 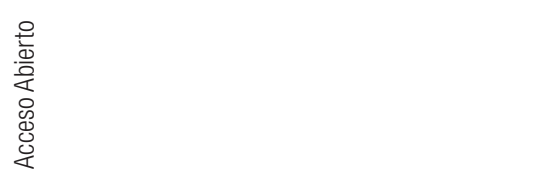 \\
\hline 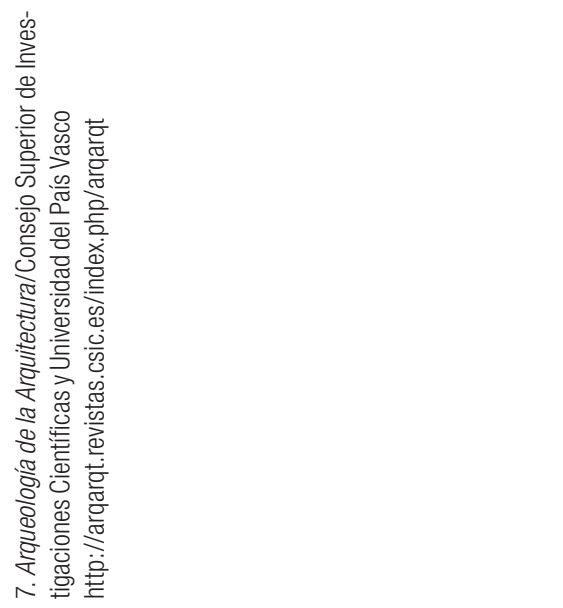 & 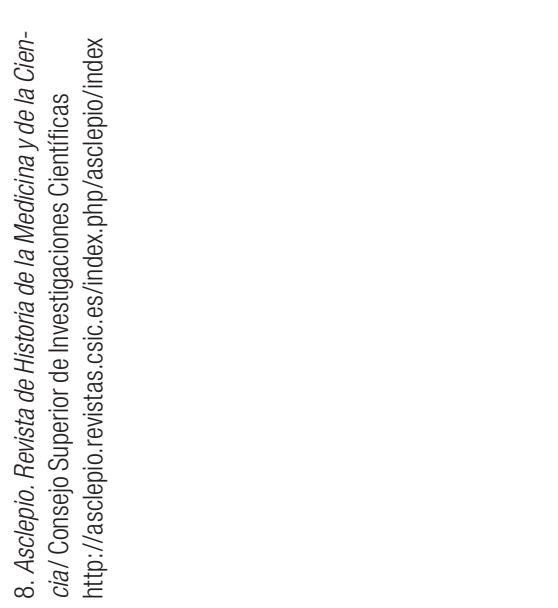 \\
\hline
\end{tabular}




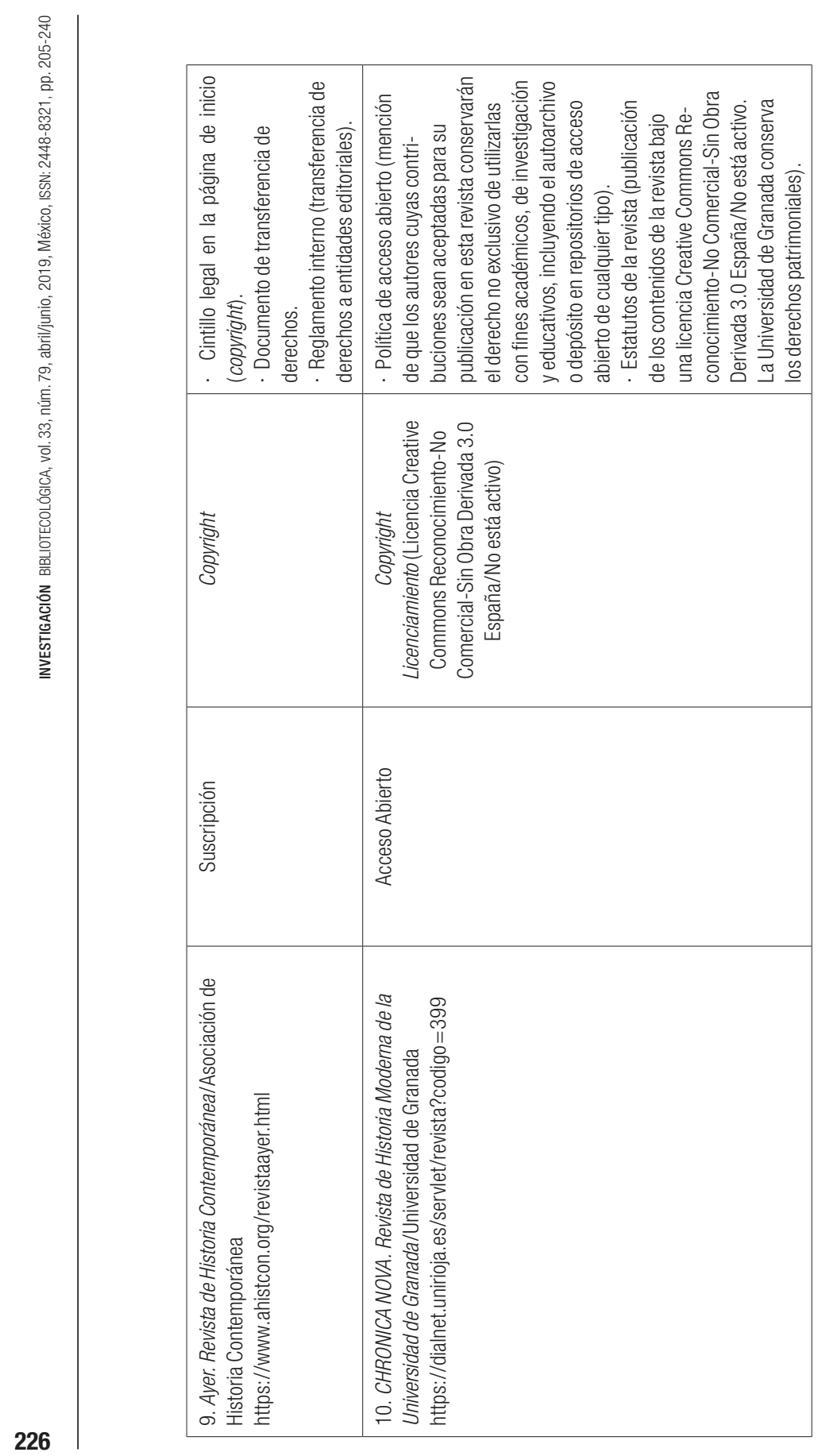




\begin{tabular}{|c|c|c|}
\hline 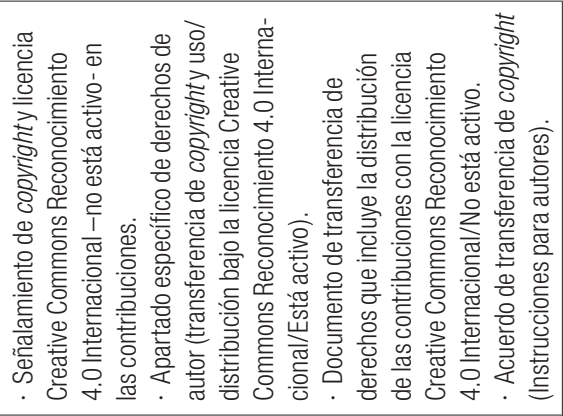 & 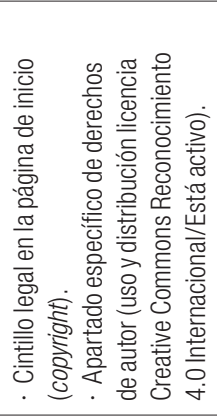 & 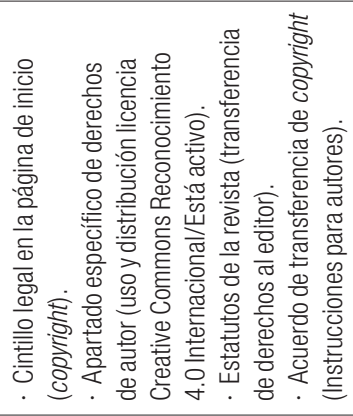 \\
\hline 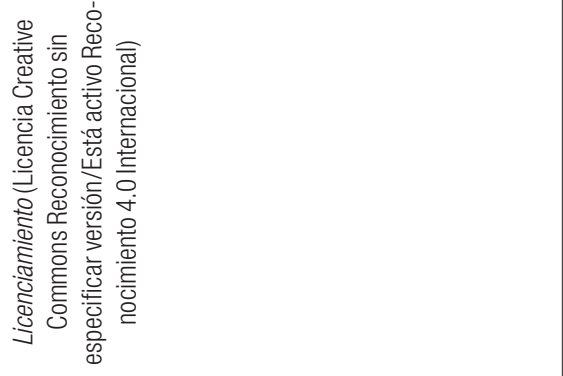 & 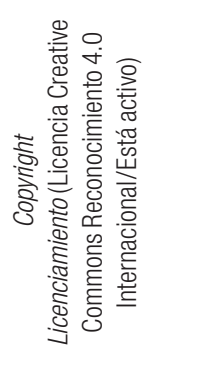 & 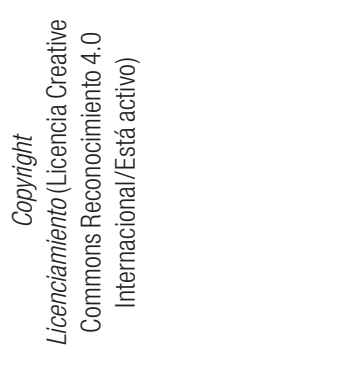 \\
\hline 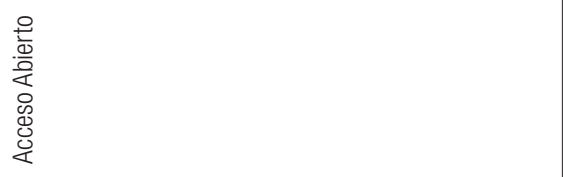 & 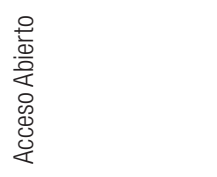 & 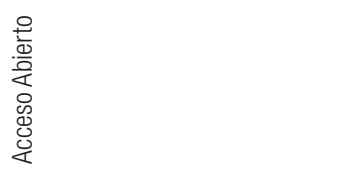 \\
\hline 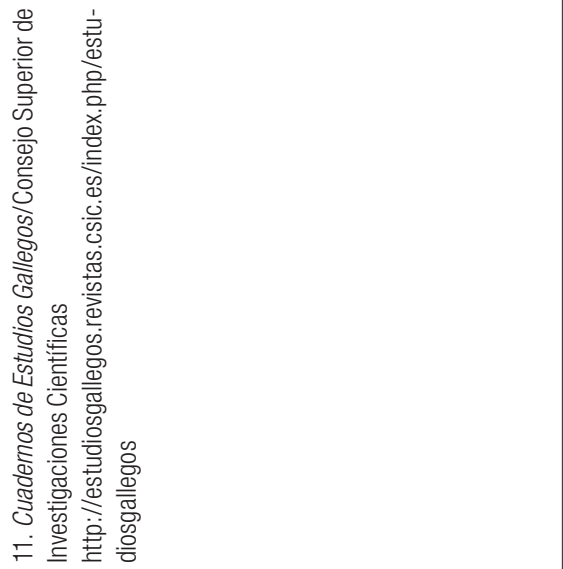 & 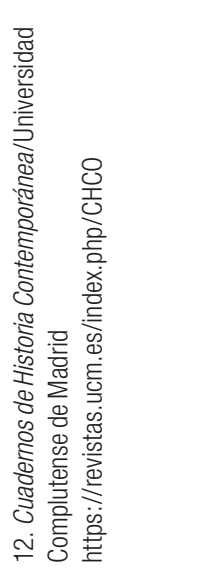 & 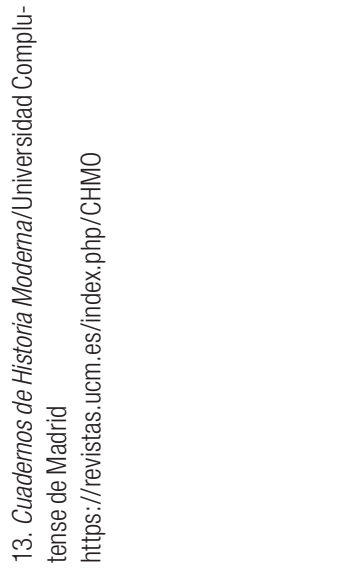 \\
\hline
\end{tabular}

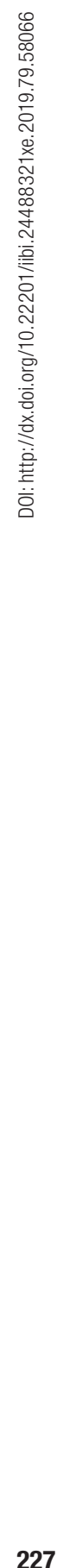




\begin{tabular}{|c|c|c|}
\hline 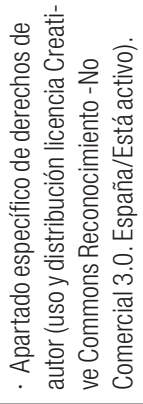 & 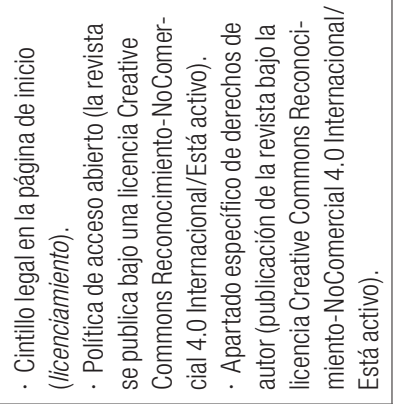 & 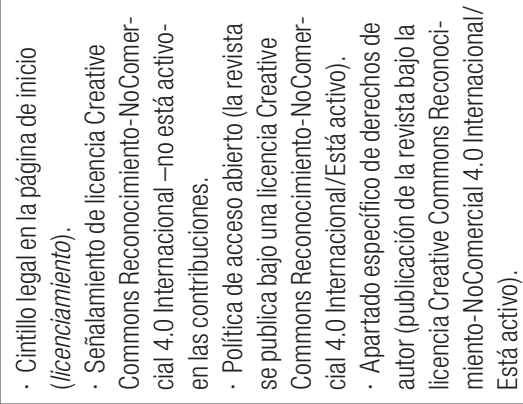 \\
\hline 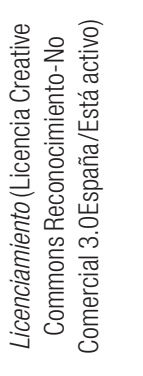 & 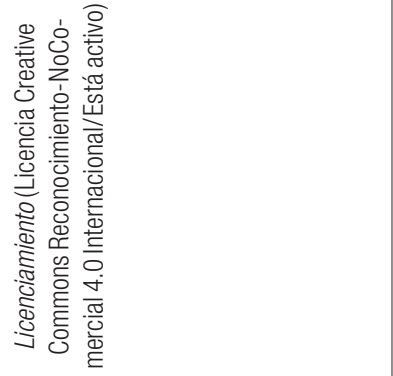 & 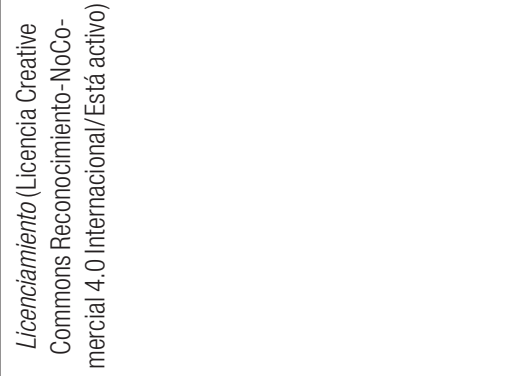 \\
\hline $\begin{array}{l}\frac{0}{0} \\
\frac{0}{0} \\
\frac{0}{0} \\
0 \\
0 \\
0 \\
\frac{0}{0} \\
\frac{0}{4}\end{array}$ & 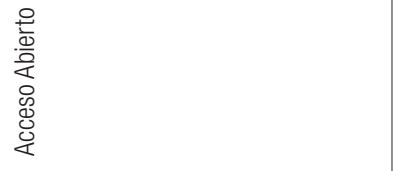 & 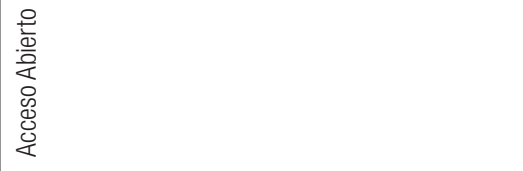 \\
\hline 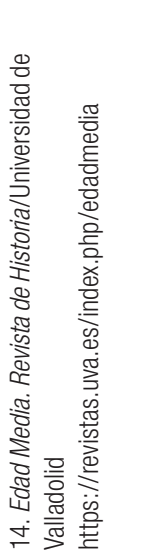 & 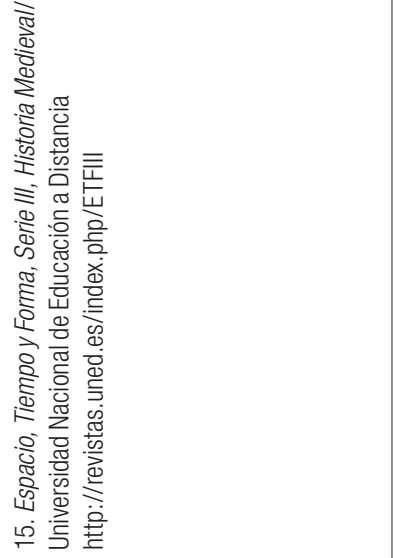 & 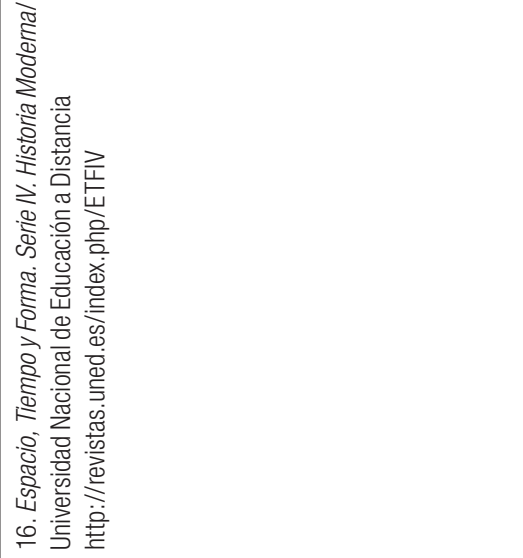 \\
\hline
\end{tabular}




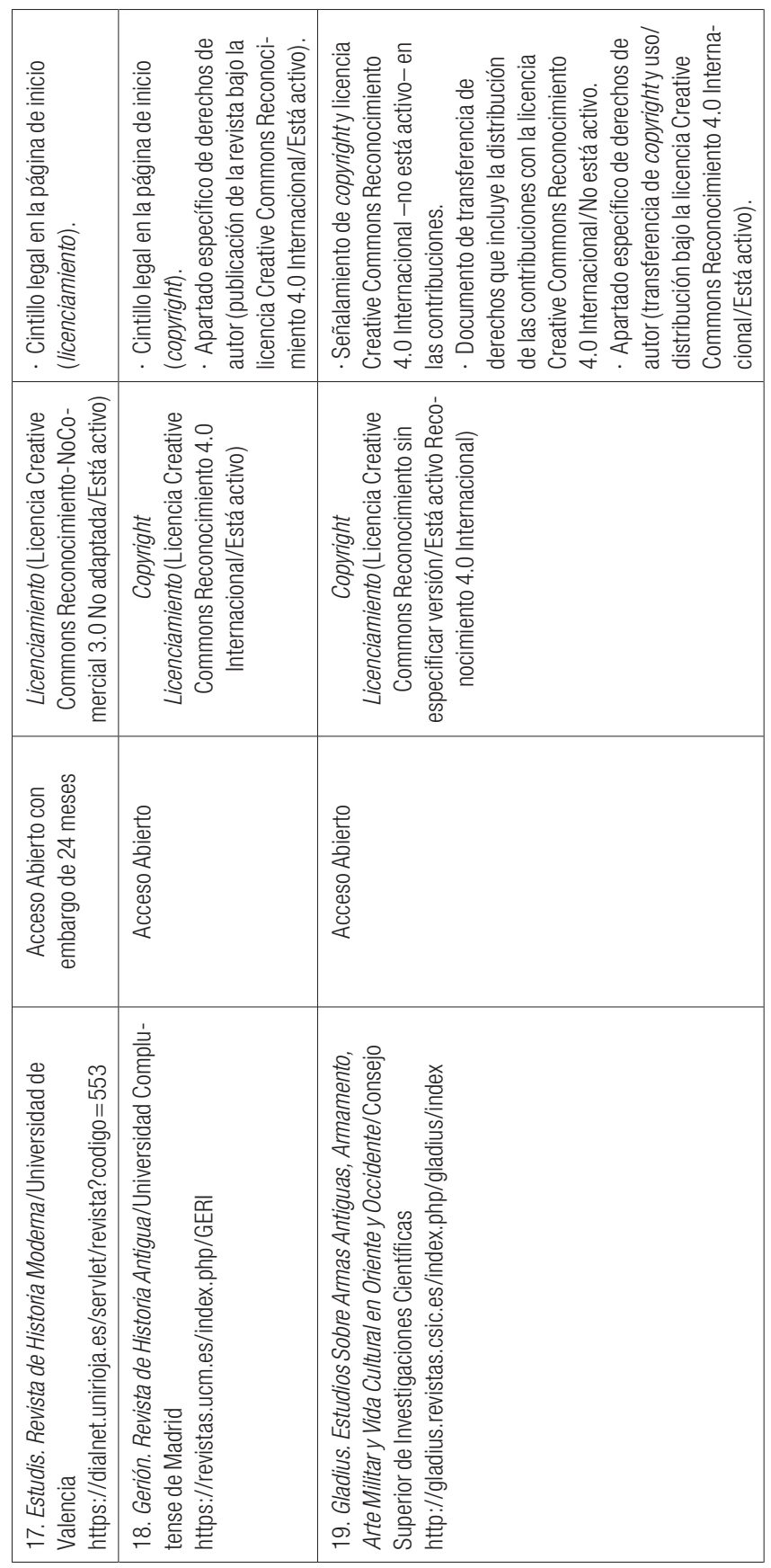




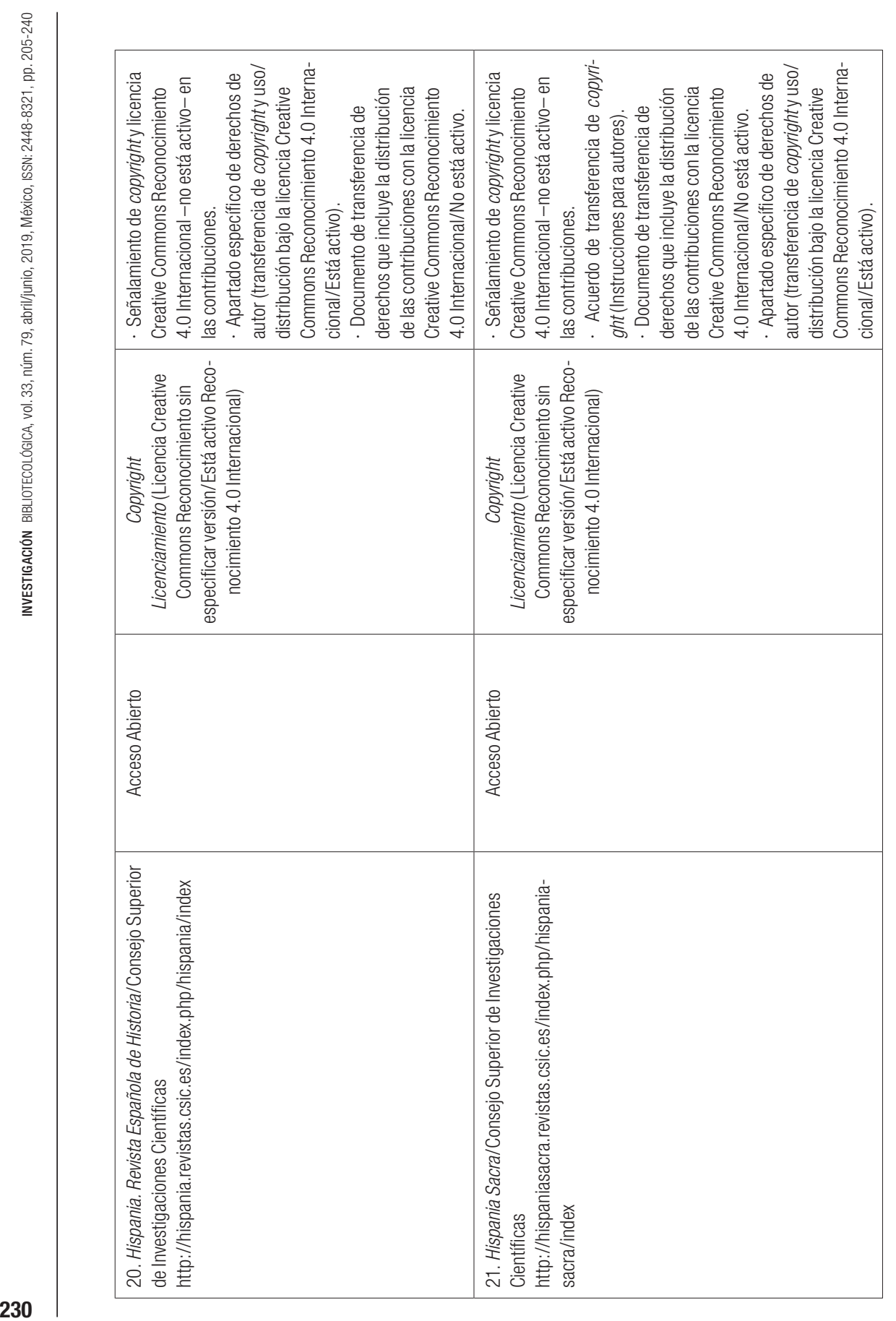




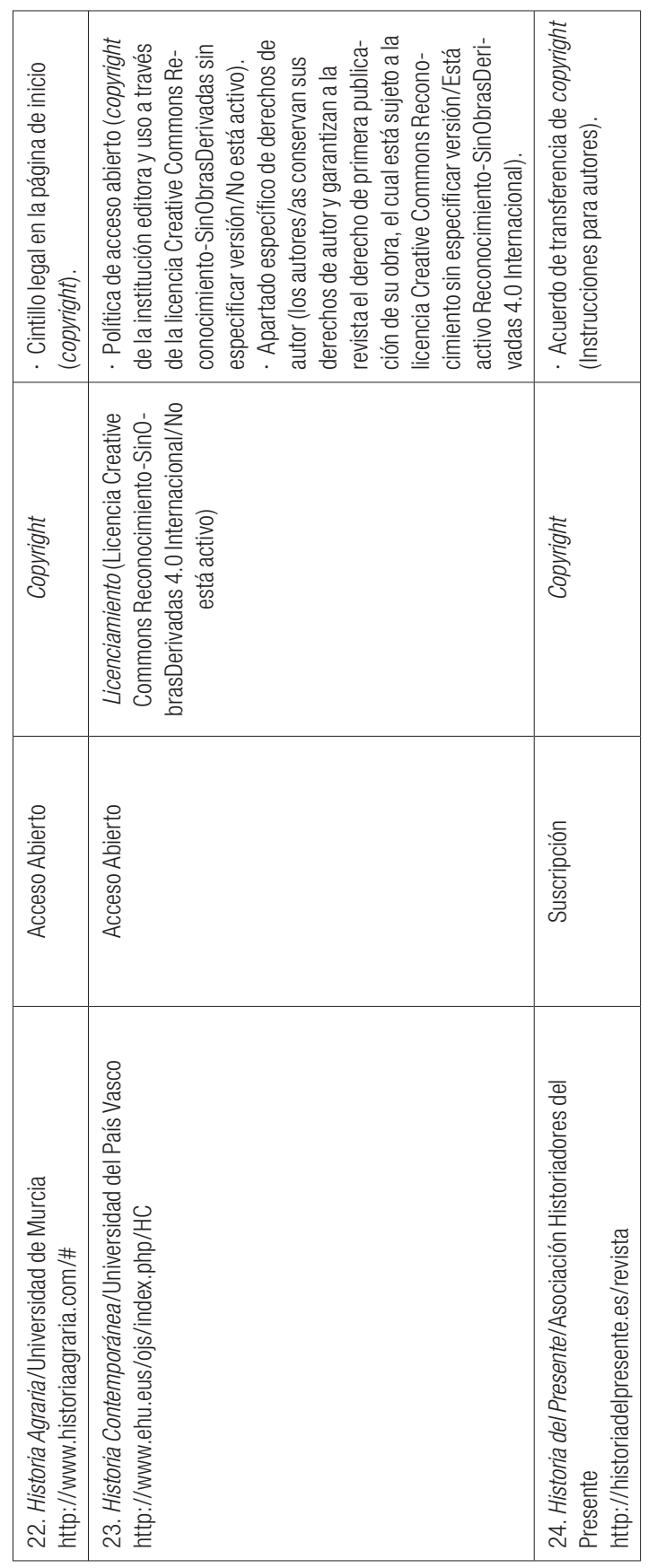




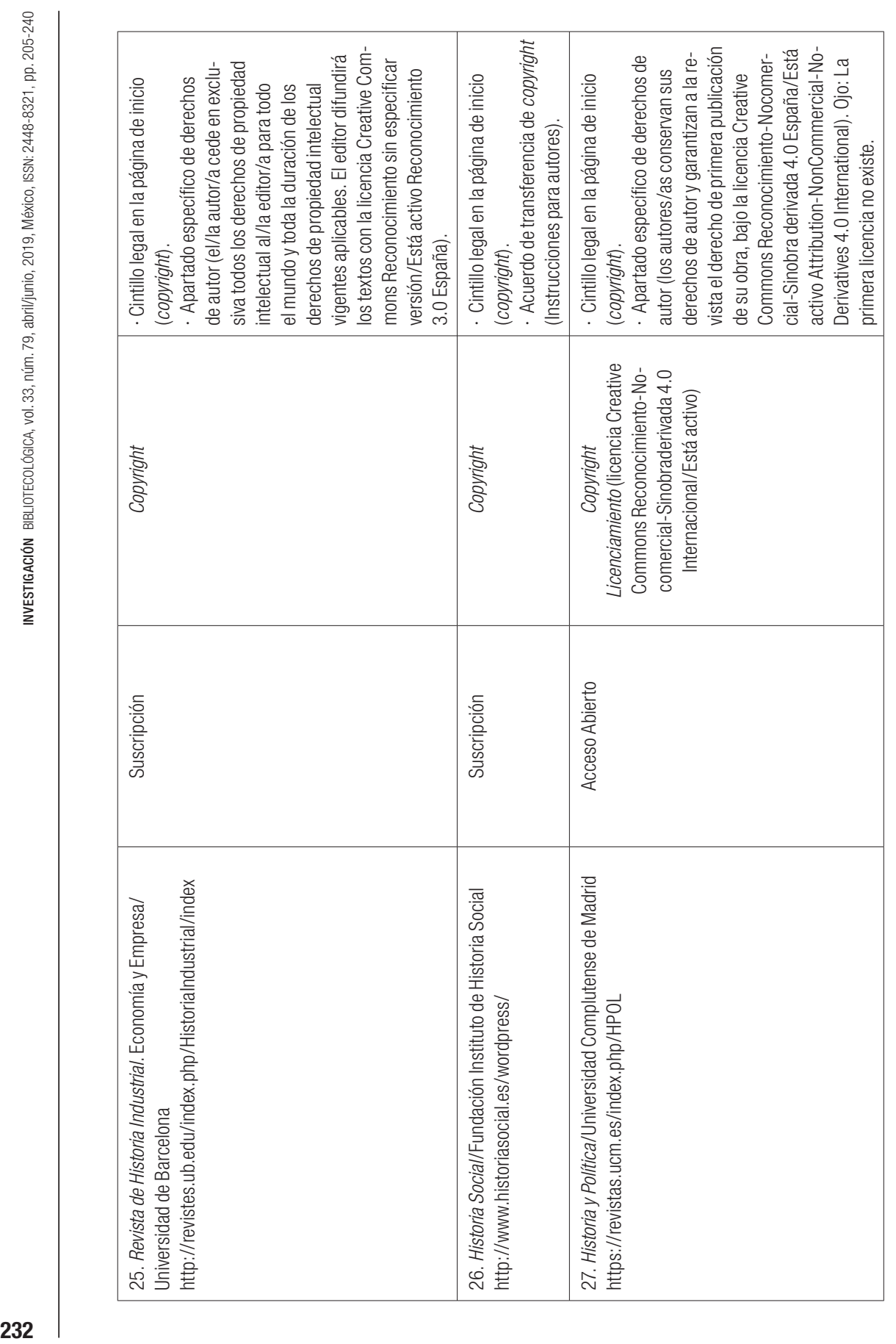




\begin{tabular}{|c|c|c|}
\hline 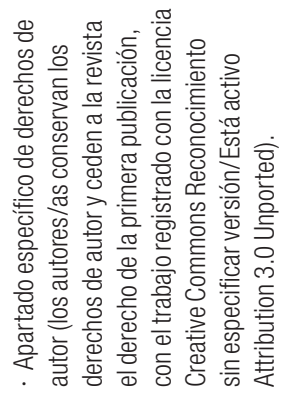 & $\begin{array}{l}\text { 意 } \\
\text { 竞 }\end{array}$ & 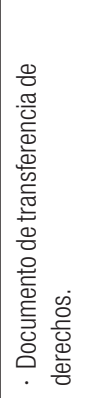 \\
\hline 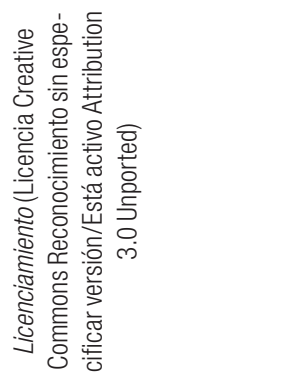 & 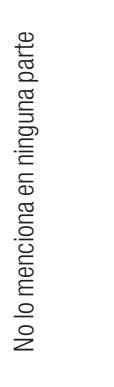 & 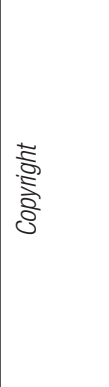 \\
\hline 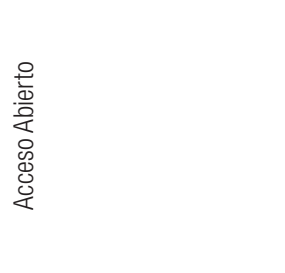 & 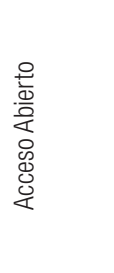 & 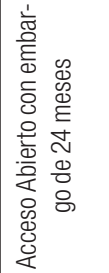 \\
\hline 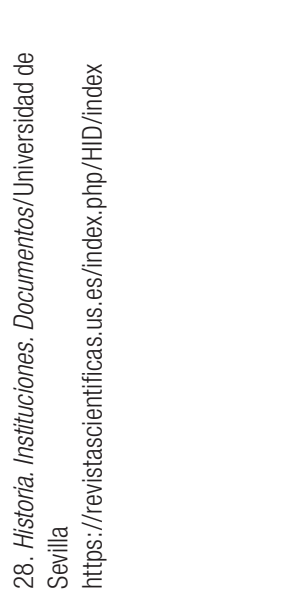 & 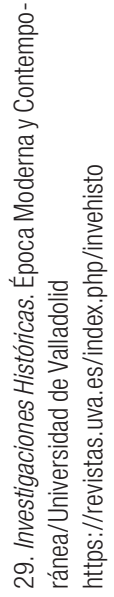 & 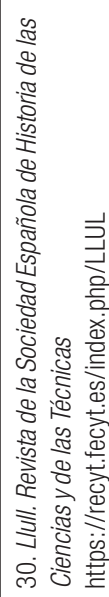 \\
\hline
\end{tabular}




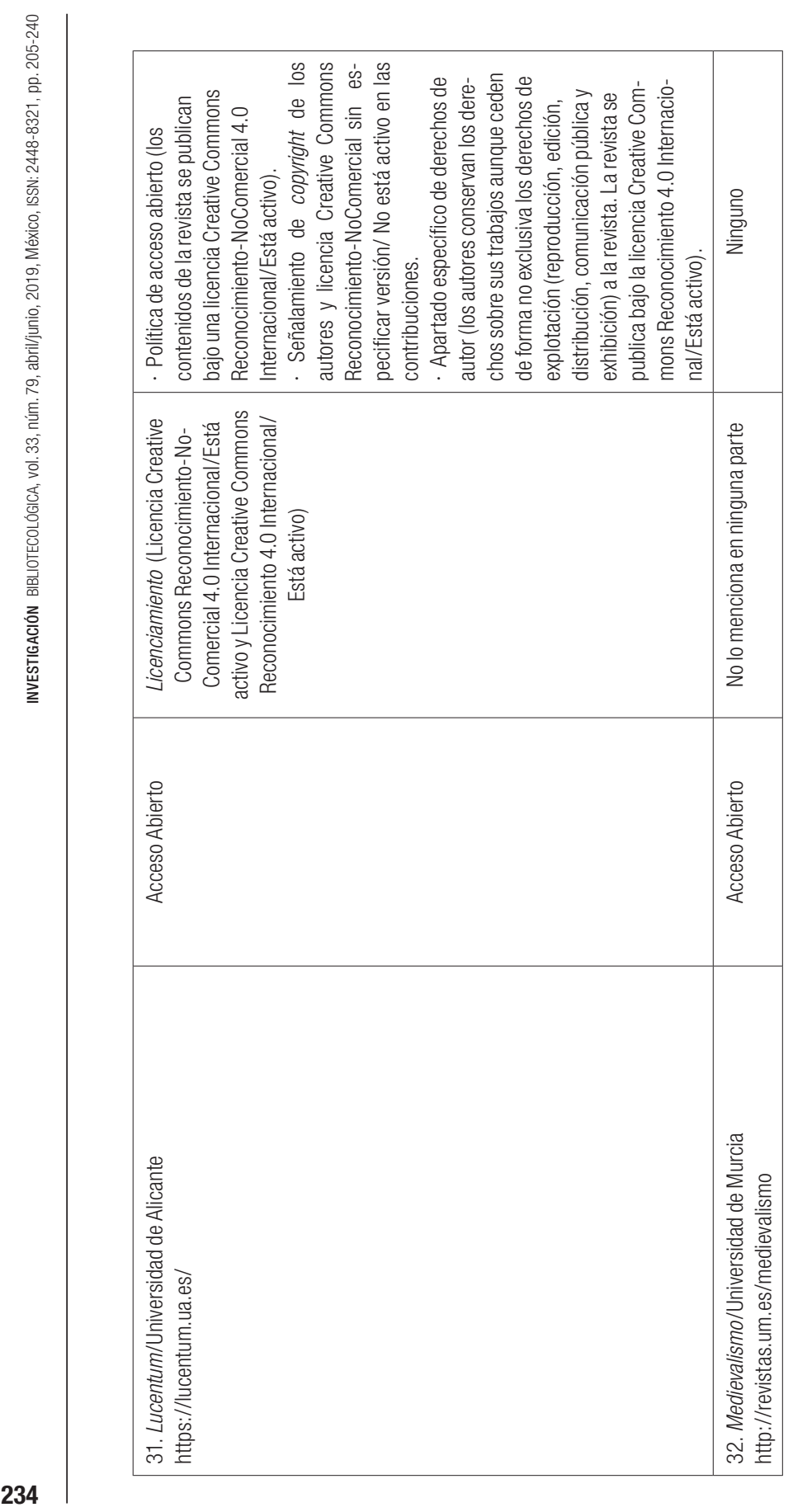




\begin{tabular}{|c|c|}
\hline 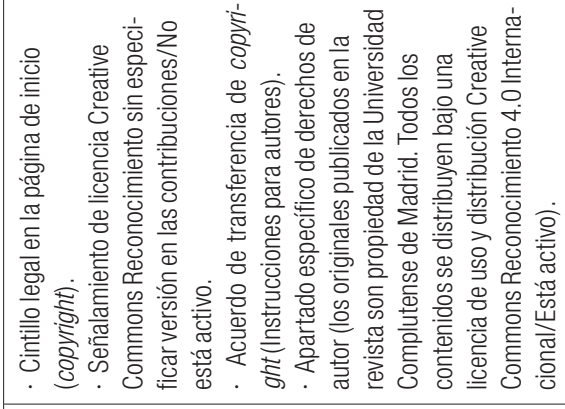 & 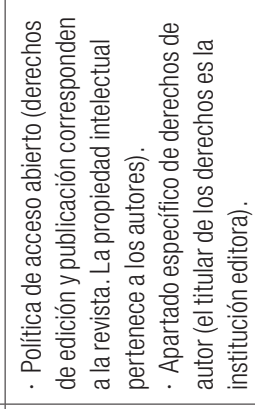 \\
\hline 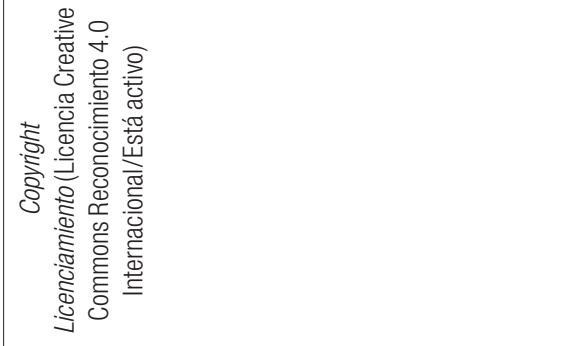 & $\begin{array}{l}\frac{\pi}{5} \\
\text { so } \\
\text { ᄋ }\end{array}$ \\
\hline 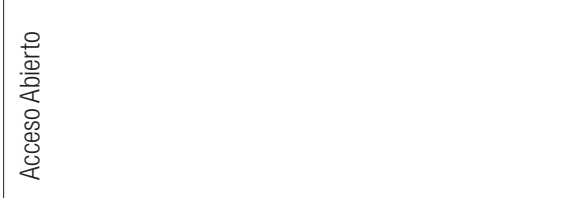 & 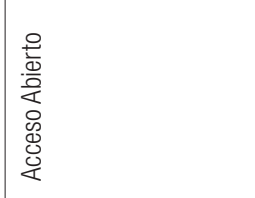 \\
\hline 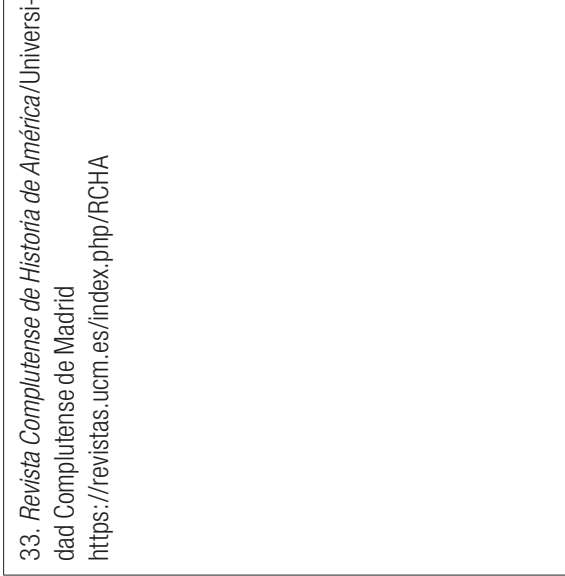 & 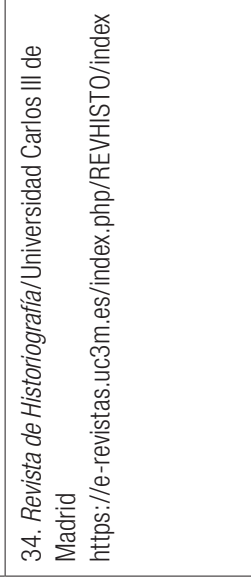 \\
\hline
\end{tabular}




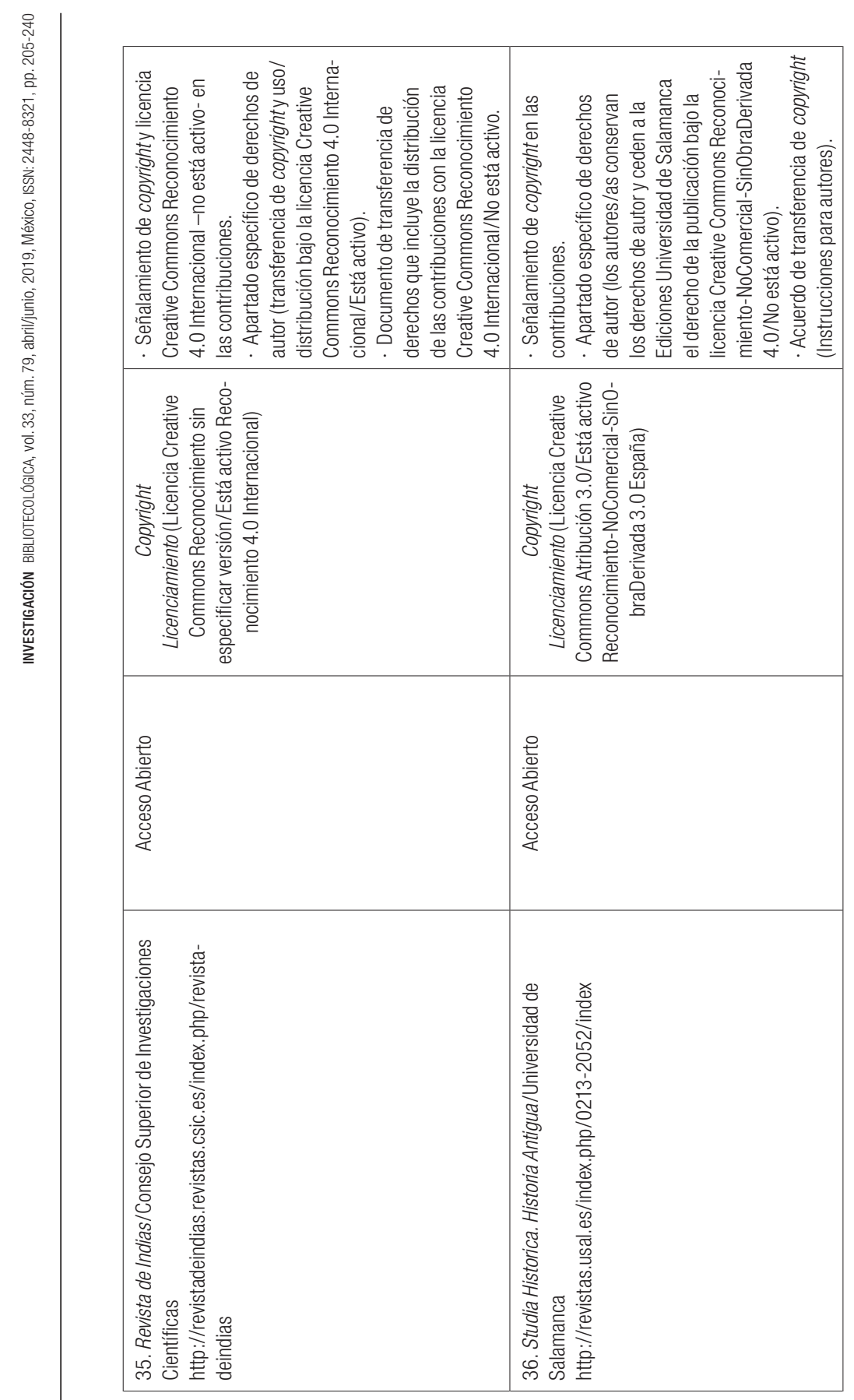




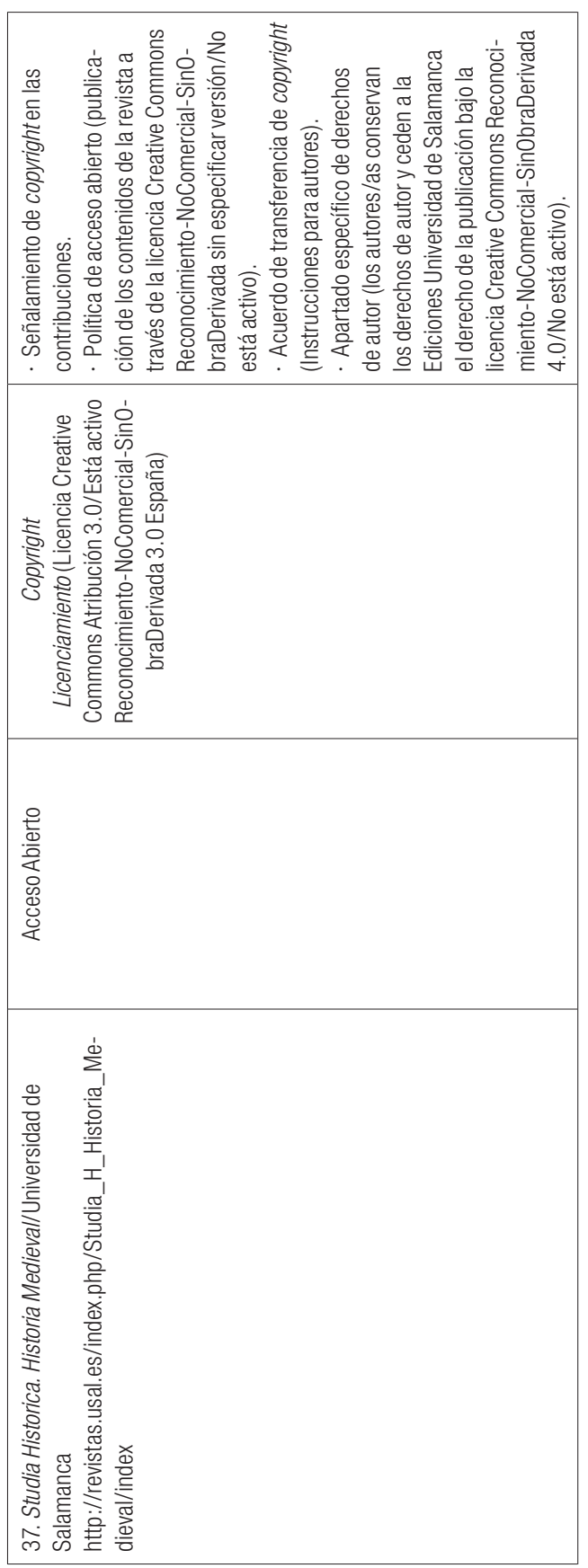




\begin{tabular}{|c|c|c|c|}
\hline 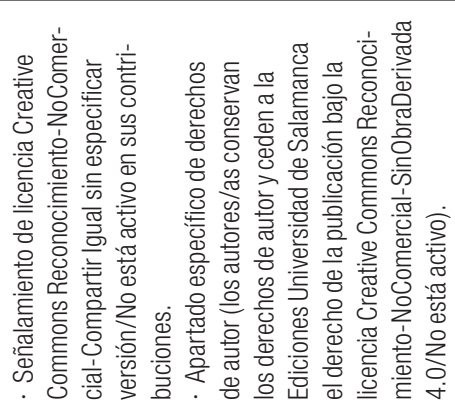 & & 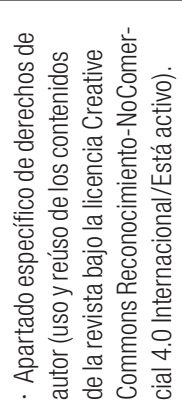 & 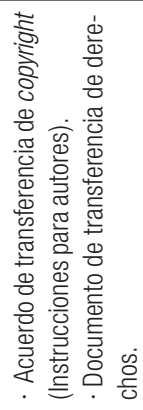 \\
\hline 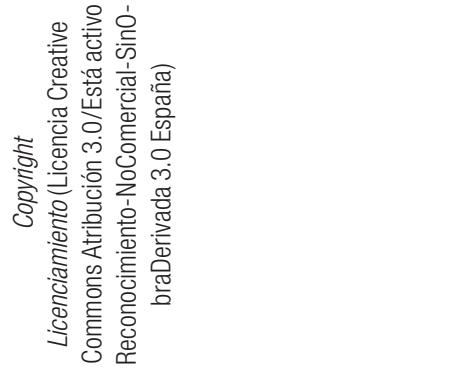 & & 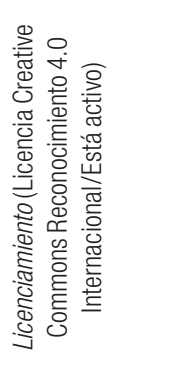 & 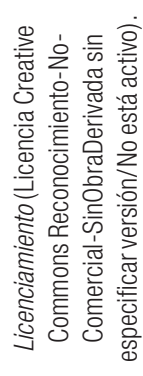 \\
\hline $\begin{array}{l}\frac{0}{0} \\
\frac{0}{0} \\
\frac{0}{0} \\
8 \\
0 \\
\frac{0}{0} \\
\frac{0}{4}\end{array}$ & $\begin{array}{l}0.00 \\
\stackrel{0}{x} \\
\stackrel{0}{\Sigma}\end{array}$ & 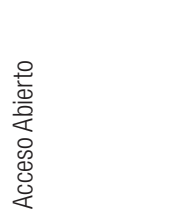 & 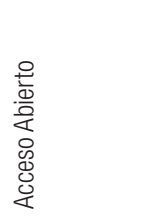 \\
\hline 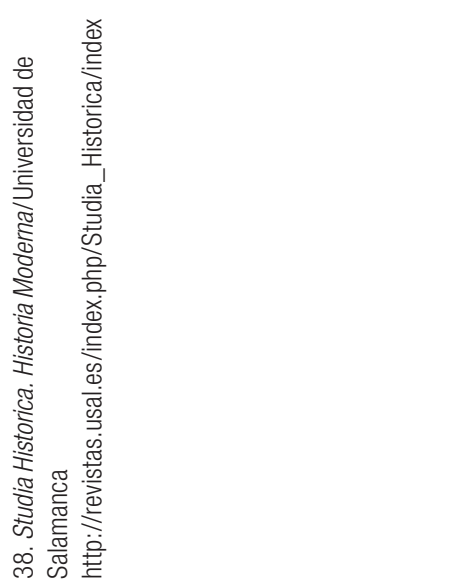 & & 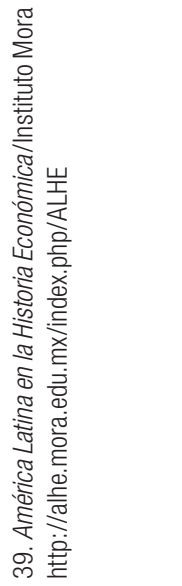 & 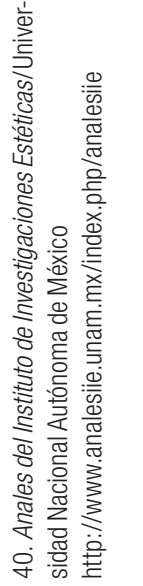 \\
\hline
\end{tabular}




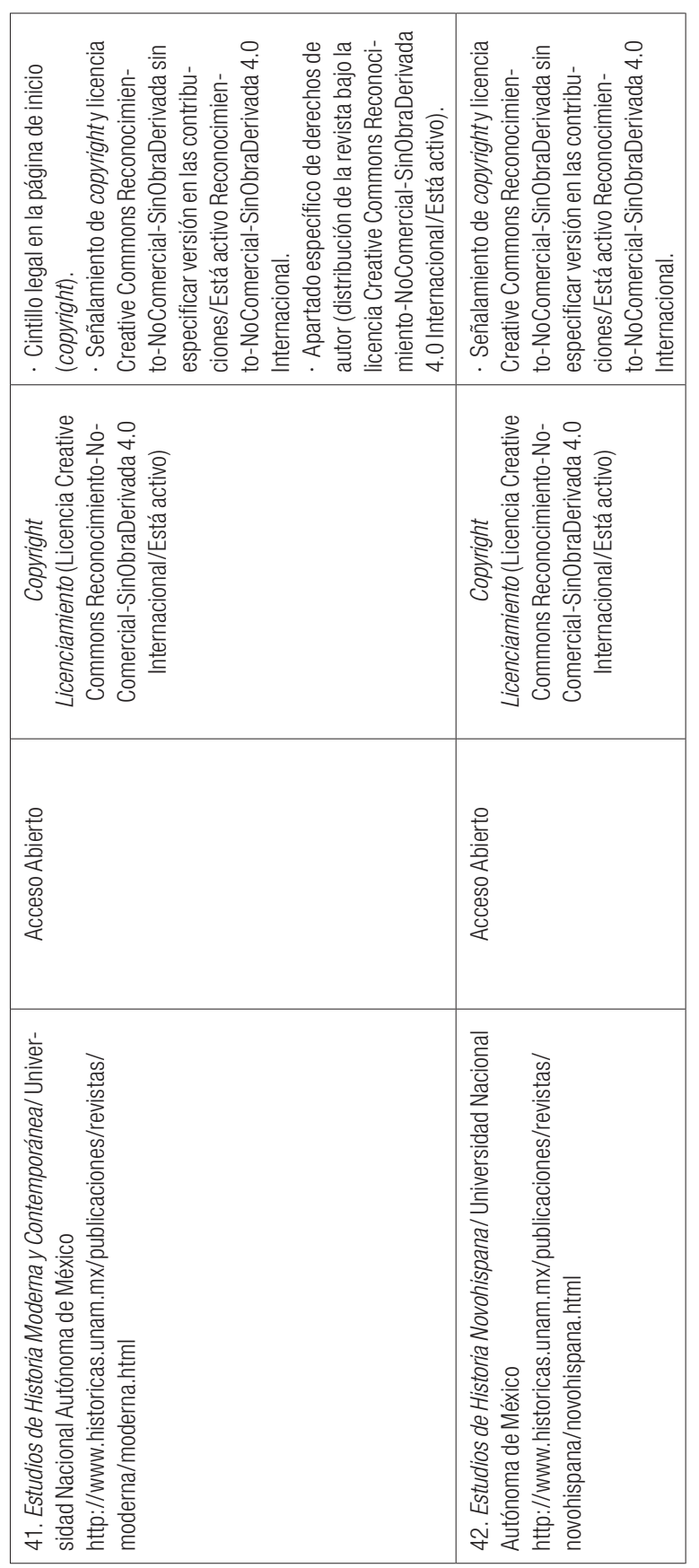




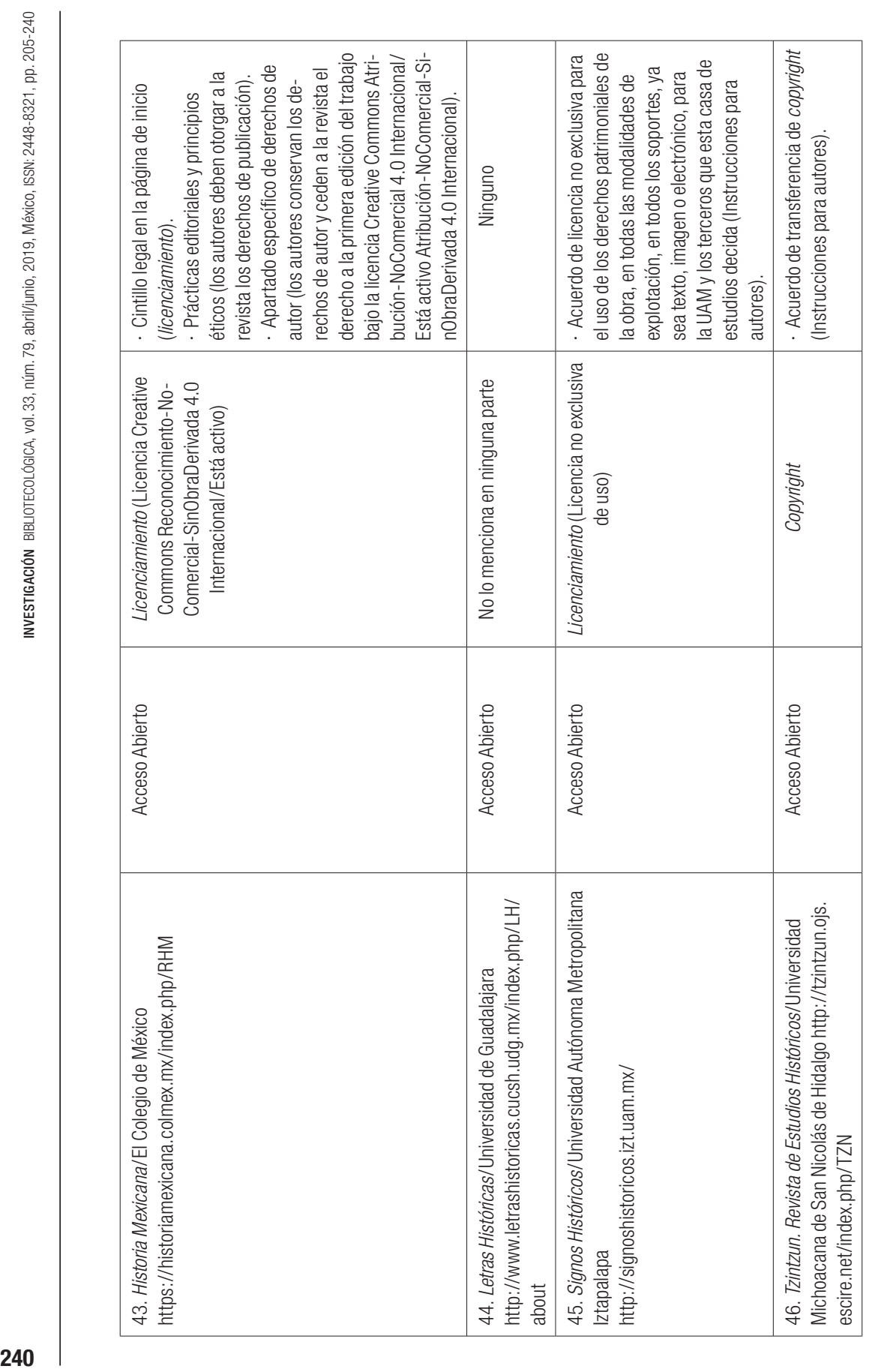

